\title{
Educação em Ciências nos Tempos de Pós-Verdade: Reflexões Metafísicas a partir dos Estudos das Ciências de Bruno Latour
}

\section{Science Education in Post-Truth Age: Metaphysical Reflections From Bruno Latour's Science Studies}

\author{
Nathan Willig Lima ${ }^{(0)}$ Brasil \\ Pedro Antônio Viana Vazata ${ }^{\circledR}$ Brasil \\ Fernanda Ostermann ${ }^{\circledR}$ Brasil \\ Claudio José de Holanda Cavalcanti \\ Andreia Guerra \\ Brasil
}

O termo pós-verdade foi escolhido como palavra do ano pelo dicionário Oxford em 2016. Hoje, vemos a proliferação do termo fake news bem como a divulgação de visões alternativas à ciência, como o terraplanismo, terapias integrativas, e negação do aquecimento global antropogênico. Não raramente, o pós-modernismo é responsabilizado por subsidiar teoricamente tais movimentos. No presente artigo, defendemos a tese de que tanto o discurso oficial da ciência (discurso modernista) bem como algumas de suas principais críticas (inclusive o pós-modernismo) parecem ser proposições que sustentam o atual cenário de produção e proliferação de pós-verdades. A partir dos Estudos das Ciências de Bruno Latour, fazemos uma reflexão sobre as bases metafísicas de tais perspectivas e apresentamos uma explicação de como se dá a formação da "pós-verdade" através de dois mecanismos distintos, a dizer, a apresentação de uma visão reduzida da natureza da ciência e o apagamento da rede que sustenta proposições científicas. Defendemos, também, como a Educação em Ciências pode se valer de uma base metafísica alternativa, desenvolvida por Latour e colaboradores em dialogia com diferentes vertentes filosóficas e sociológicas, contribuindo para a formação de cidadãos capazes de se posicionar criticamente no cenário sociocientífico contemporâneo.

Palavras-chave: Pós-Verdade; Metafísica; Estudos das Ciências; CTS; Latour.

The term post truth was chosen as the word of the year by the Oxford dictionary in 2016. Today we see the proliferation of the term fake news as well as the dissemination of alternative views to science, such as "flat Earth", integrative therapies, and anthropogenic global warming denial. Usually, postmodernism is blamed for subsidizing such movements theoretically. In the present article, we defend the thesis that both, the official discourse of science (modernist discourse) and its main criticisms (including 
postmodernism) seem to be propositions that sustain the contemporary scenarios of production and proliferation of post-truths. Departing from Bruno Latour's Science Studies, we reflect on the metaphysical basis of such perspectives and present an explanation to the formation of the "post-truth" through two different mechanisms, i.e, the presentation of a reduced vision of nature of science and the erasure of the network that sustain scientific propositions. We also defend that Science Education can adopt an alternative metaphysical basis, developed by Latour and collaborators in dialogue with different philosophical and sociological currents, contributing to the formation of citizens able to have a critical position in the contemporary socioscientific scenario.

Keywords: Post-Truth; Metaphysics; Science Studies; STS; Latour.

\section{Introdução}

O final do século XIX e o início do século XX foram marcados pela ascensão do cientificismo na sociedade moderna e da filosofia positivista na ciência. No discurso de demarcação e significação epistemológica, revisitou-se o privilégio do Empirismo, como o que ocorre no Tratactus de Wittgenstein (1968) e nas obras do Círculo de Viena (Goldstein, 2008). Ademais, a crença na racionalidade científica motivou a concepção de homem moderno, civilizado e científico em oposição a um passado irracional, mítico, não civilizado. Tal visão sobre a superioridade da ciência em comparação a outras formas de conhecimento, apoiada por pressupostos empiristas ou racionalistas - como na epistemologia de Popper (2008) - também subsidiou a formação de concepções de ciência típicas do discurso moderno, atribuindo-lhe características como neutralidade e linearidade (Deconto, 2014), além de promover uma visão salvacionista da humanidade (Auler, \& Delizoicov, 2001).

A partir da década de cinquenta do século XX, entretanto, o clima de euforia com relação ao ideal científico passou a ser paulatinamente desacelerado em favor de um sentimento de descrença e desmotivação em relação não só à ciência, mas à humanidade - marcando o início de um período pós-modernista (Lopes, 2013). Os impactos da segunda guerra mundial, incluindo o avanço da ciência nuclear e sua inata miscigenação com interesses geopolíticos (Deconto, 2014), bem como estudos ambientalistas (Carson, 1994), permitiram a formação de um contexto em que o ideal cientificista (e os mitos a ele atrelados) pudesse ser colocado sob suspeição. No campo da História e Filosofia da Ciência, especificamente, a proposição de visões não absolutistas, como a defendida em A Estrutura das Revoluções Científicas (Kuhn, 1996), exemplifica justamente o surgimento da possibilidade de se pensar sobre a ciência fora do objetivismo ontológico e epistemológico herdados da modernidade, permitindo a reflexão sobre a ciência em suas relações com a sociedade e com a cultura. Tais movimentos abriram espaço para se questionar o local privilegiado ocupado pelo discurso científico, subsidiando o surgimento de visões alternativas.

Apesar dos benefícios que podem advir da oposição ao discurso hegemônico 
e colonialista da ciência (Santos, \& Meneses, 2009), os movimentos de relativização do conhecimento e da verdade produziram efeitos colaterais não esperados. Em 2016, o Dicionário Oxford elegeu, como palavra do ano, o termo pós-verdade, "denotando circunstâncias em que fatos objetivos são menos influentes em moldar a opinião pública do que apelos emocionais e crenças pessoais" (Oxford Dictionary, 2016, tradução nossa). Hoje, na mesma perspectiva, observamos o uso crescente do termo fakes news nas redes sociais (Idoeta, 2018). Ademais, percebe-se, atualmente, a adoção e divulgação de perspectivas alternativas às científicas, como o terraplanismo (Alvim, 2017), a defesa de terapias alternativas (Lima, \& Nascimento, 2018), a negação do efeito das vacinas (Corrêa, 2014) e a negação do aquecimento global antropogênico (Junges, \& Massoni, 2018). Tais visões tensionam a opinião pública sobre temas que têm não somente relevância intelectual, mas que impactam concretamente o futuro de nossa sociedade. O desenvolvimento científico e tecnológico hibridizou a humanidade com o resto do planeta de tal forma que aquilo que se constrói sobre a natureza afeta os caminhos da sociedade e aquilo que se disputa na sociedade afeta o caminho da natureza. Dessa forma, a discussão sobre pós-verdade é, também, uma discussão sobre o futuro de nossa existência e sobrevivência no período do Antropoceno (Arènes, Latour, \& Gaillardet, 2018; Latour, 2014; Latour \& Lenton, 2018).

Pensadores contemporâneos responsabilizam o pensamento pós-moderno por dar suporte teórico para a formação de pós-verdades (Mcintyre, 2018). No presente artigo, entretanto, trilhamos um caminho alternativo e defendemos a tese de que tanto o discurso cientificista (moderno) quanto as principais críticas a ele (incluindo o pósmodernismo) possuem bases metafísicas que são responsáveis por subsidiar a produção e proliferação de "cenários de pós-verdades". Propomos que a maneira como a realidade é apresentada por todos esses discursos inviabiliza a opinião pública de se posicionar frente às controvérsias sociotécnicas através de dois mecanismos distintos, a dizer, a apresentação de uma visão reduzida da natureza da ciência e o apagamento da rede que sustenta proposições científicas.

Para estruturar tal tese, fazemos uma discussão sobre as bases metafísicas do discurso da ciência moderna bem como de algumas de suas principais críticas a partir dos Estudos da Ciência de Bruno Latour. Na sequência, apresentamos uma visão metafísica alternativa, desenvolvida e articulada por Latour e colaboradores em seus Estudos das Ciências em dialogia com a Sociologia Monadal de Gabriel Tarde (2007), a Sociologia Simétrica de Michel Callon (1984) e a Filosofia das Proposições de Alfred Whitehead (1978). A partir de tais reflexões filosóficas, redefinimos o conceito de pósverdade e, opondo-nos ao conceito do Dicionário Oxford, apresentamos uma explicação sobre como tanto a adoção das visões cientificistas quanto das demais críticas corrobora a propagação de pós-verdades. Por fim, comentamos algumas possibilidades que podem ser levadas em consideração para que se possa desenvolver uma Educação em Ciências com uma base metafísica alternativa (em consonância com a visão de Latour e colaboradores) - a qual não recai nem na visão absolutista nem relativista das demais 
vertentes e que pode ser uma forma de contribuir para o debate público sobre o conflito entre visões científicas e alternativas à ciência.

\section{Reflexões sobre Metafísica e Ciência}

Em A Esperança de Pandora, Latour (2017) destaca que acredita em "realidade" quando responde a questionamentos de um psicólogo ${ }^{1}$. Em sua resposta, o filósofo francês ainda acrescenta que sabemos hoje mais do que sabíamos no passado, e que a ciência é cumulativa ${ }^{2}$, uma visão totalmente antagônica ao que se relata, usualmente, sobre Latour (Slezak, 1994). Como pode um dos maiores críticos da ciência e, talvez, um dos grandes colaboradores para o enfraquecimento de sua credibilidade (Latour, 2004b) defender tal posicionamento tão "conservador"?

Para explicar suas repostas, Latour indica o caminho a ser seguido: "precisamos realmente engolir esses bocados insípidos de filosofia escolar para compreender a pergunta do psicólogo? Temo que sim, porque de outra forma as inovações dos estudos científicos ${ }^{3}$ permanecerão invisíveis."(Latour, 2017, p.19). Da mesma forma que não se podem entender os Estudos das Ciências sem analisar suas bases metafísicas, não é possível entender o problema da pós-verdade sem se remeter à visão ontológica que a sustenta. Para discutir tal questão, apresentamos algumas reflexões de Latour sobre as bases metafísicas da ciência e de algumas das críticas ao discurso cientificista.

\section{O Discurso Oficial da Ciência}

Latour (1999) indica a proposição da dualidade mente-corpo feita por René Descartes como um dos marcos inaugurais do discurso da ciência moderna ${ }^{4}$. Mais especificamente, Latour discorre sobre a tentativa de Descartes de, a partir de tal dualidade, explicar "como uma mente isolada podia estar absolutamente, e não relativamente, segura de um objeto do mundo exterior" (Latour, 2017, p.16). Tal separação entre uma mente interna e um mundo material externo, que dá origem ao que alguns autores denominam de paradigma da dualidade mente-corpo (Searle, 2004), gera, segundo Latour, a seguinte questão: como é possível garantir a existência do mundo exterior e a confiabilidade daquilo que percebemos? A célebre frase de Descartes cogito ergo sum (penso, logo existo) indica que a garantia da existência da mente é fornecida pela existência do pensamento. Por outro lado, a garantia da existência do mundo exterior, no argumento cartesiano, demanda a existência de Deus (Latour, 1999b; Searle, 2004).

1 Algumas vertentes do pós-modernismo consideram que a realidade é um efeito do discurso (discutiremos tal visão na sequência do texto). Tal pergunta a Latour se deve, provavelmente, ao fato de ele ser confundido como pós-moderno (Lima, Ostermann, \& Cavalcanti, 2018a).

2 A ideia de que a ciência avança de forma cumulativa é questionada pelo menos desde a obra de Thomas Kuhn (1996).

3 "Estudos Científicos" é a tradução feita para "Science Studies", o que temos chamado nesse texto de "Estudos das Ciências".

4 A contribuição de Descartes para o desenvolvimento da ciência e da cultura moderna, como aponta Latour, é inegável. No caso da Educação em Ciências contemporânea, diversos trabalhos discutem as ideias do físico, filósofo e matemático francês, principalmente na Física (Ponczek, 2000; Porto \& Porto, 2009). 
Nessa concepção, aquilo que caracteriza nossa humanidade está na mente não-material, visto que a matéria é totalmente inerte.

A consolidação da dicotomia sujeito-natureza ocorre, segundo Latour (1999b, 2013), no período iluminista, principalmente dentro da construção filosófica de Immanuel Kant, segundo a qual os "objetos-em-si" são inacessíveis ao "ego transcendental" (Kant, 2005). Na filosofia kantiana, o encontro entre os seres e os objetos só é possível mediante um intermediário - o fenômeno. Nessa proposição, somos enclausurados em nossas próprias cognições, cuja validade só é garantida por um juízo a priori ${ }^{5}$ (Latour, 1999b). A validade do conhecimento se dá, portanto, pela validade de tais juízos, absolutos e universais ${ }^{6}$, constructos próprios da mente apartada da matéria. Partindo de tal visão, Kant define iluminação como a capacidade de pensar por si só: "O lema da iluminação é, portanto: Sapere aude! [Ouse ser sábio!] Tenha coragem para usar seu entendimento próprio!"(Kant, 2009, p. 6, tradução nossa). Tal descrição sobre desenvolvimento intelectual reforça a noção de sua filosofia de que a construção do conhecimento se dá "no sujeito", internamente7. Em sua opus magnum, ademais, Kant (2005) usa sua metafísica para justificar e validar o conhecimento científico. Em síntese, a descrição metafísica que subsidia a ciência moderna, a separação entre natureza e sociedade, pode ser representada no esquema da Figura 1.

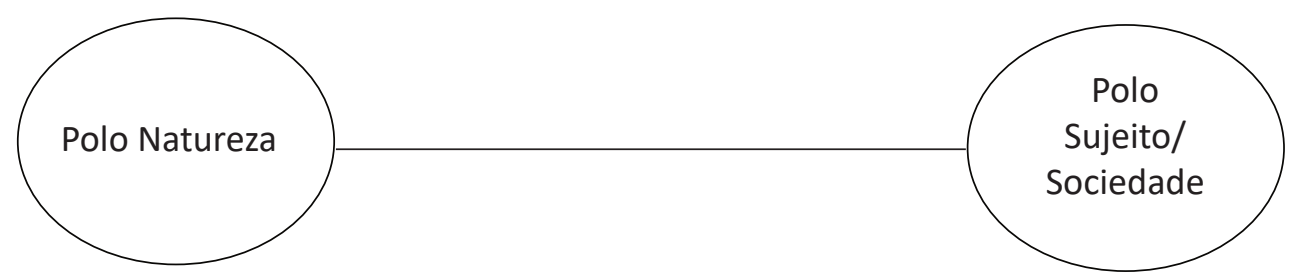

Figura 1. Adaptado de (Latour, 1992). De um lado há o sujeito, enclausurado sobre si mesmo, e os sujeitos entre eles (sociedade ${ }^{8}$ ). Do outro lado há a natureza, o campo dos objetos-em-si. Ambos os polos ontológicos estão irreversivelmente apartados.

5 O pensamento kantiano é tão forte na estrutura da filosofia ocidental que ela demarca, inclusive, suas subáreas. Uma vez que os objetos-em-si existem independentemente e de forma inacessível ao ego transcendental (a não ser pela intermediação do fenômeno), diferem-se duas áreas: a primeira, a ontologia, é o estudo dos seres-em-si; e a segunda, a epistemologia, é o estudo do conhecimento (Pessoa Jr., 2009)

6 Kant (2005) define dois critérios para o reconhecimento de um juízo a priori: ele deve ser absoluto e universal. Como exemplos, o autor traz a noção de causalidade, a geometria euclidiana, o espaço e o tempo - conceitos cuja universalidade foram colocados sob suspeição na Física Moderna. Tal percepção fez Einstein, por exemplo, afirmar a impossibilidade de se propor categorias finais como supunha Kant (Einstein, 2006). Para uma discussão sobre o pensamento filosófico de Einstein em relação a Kant, sugerimos o trabalho de Dahmen (2006).

7 O centramento do processo cognitivo no sujeito, proposto por Kant, influencia diretamente a Educação e a Educação em Ciências através das teorias cognitivistas como a de Jean Piaget (Fabricius, 1983; Otte, 1998) e David Ausubel (Valadares, 2011). Ademais, podem-se encontrar, na literatura, artigos, na área de Ensino, que discutem as ideias de Kant (Lang, 2002).

8 O conceito de sociedade aparece na narrativa sobre a modernidade de Latour (1999) como uma tentativa da academia de dar conta da validade do conhecimento sem demandar o conceito de juízo a priori de Kant. Nesse sentido, Latour aponta que a validade absoluta e universal dos conceitos é trocada pela validade auferida pelo consenso social. Lakatos (1978) indica Polanyi (1946) e Kuhn (1963, 1977, 1996) como os principais defensores do consensualismo. 
A cisão entre natureza e sociedade implicou diversas outras cisões no mundo moderno, como a já mencionada distinção entre ontologia (estudo dos objetos-em-si) e epistemologia (estudo do conhecimento) e a diferenciação entre epistemologia e política (estudo da relação dos homens entre eles). Essas novas cisões representam a natureza como apolítica e trazem o seguinte problema: como que a Ciência consegue falar sobre o mundo da natureza sem lançar mão da noção de Deus como Descartes ou de juízos absolutos como Kant? O abismo ontológico que separa o mundo-em-si (natureza) das representações simbólicas (pertencentes ao "mundo" social da linguagem) criou um problema epistemológico. A ciência moderna, por mais que tente chegar ao objeto-emsi, está enclausurada no mundo da linguagem. A solução moderna, para esse dilema, foi propor que a falsidade de uma sentença científica pode ser verificada por um teste de correspondência com os entes do mundo - como na Teoria da Verdade de Tarski (Popper, 2008). Essa proposta ontológico-epistemológica dos modernos pode ser representada pelo diagrama da Figura 2.

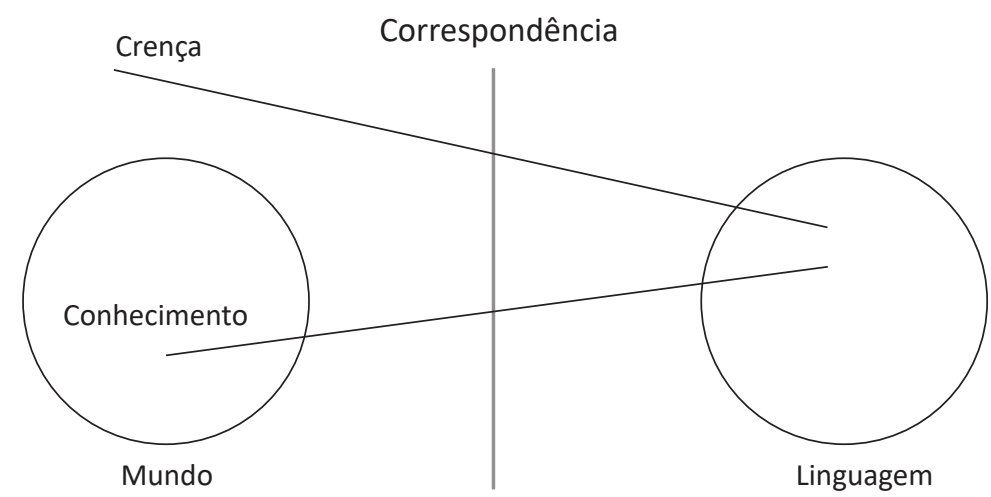

Figura 2. Adaptado de (Latour, 1999b). De um lado, temos o mundo dos objetos em si. Do outro, o mundo da linguagem e dos símbolos ${ }^{9}$. Uma sentença é dita verdadeira se ela encontra correspondência com o mundo das coisas em si e pode ser chamada de conhecimento. Uma sentença que não encontra correspondência no mundo dos objetos em si, não passa de uma crença.

Assim, no discurso científico, um ente proposto por uma teoria é existente se podemos encontrá-lo na natureza, da mesma forma que a frase "há um cachorro na porta" é verdadeira se formos até a porta e encontrarmos um cachorro. Nesse caso, dizemos que a afirmação era um "conhecimento" sobre a situação. Por outro lado, se chegarmos à porta e não encontrarmos nenhum cachorro, dizemos que tínhamos uma "crença", mas não um conhecimento. Dessa forma, a separação entre natureza e sociedade permite criar uma nova distinção, agora, entre conhecimento e crença. Toda afirmação verdadeira passa a ser explicada pelo polo natureza, enquanto toda afirmação falsa só pode ser explicada pelo polo sociedade (Latour, 1992). Tal relação conecta ontologia (metafísica) e epistemologia, inter-relação omitida pelos "epistemólogos modernos",

9 Conforme Latour (1999b) aponta, essa visão moderna resgata a noção platônica de que o mundo das Ideias é totalmente separado do mundo da matéria. 
que lançam a metafísica a um plano secundário (Latour, 1999). Colocando tal reflexão em termos do debate sobre pós-verdade, retomando o conceito do dicionário Oxford, o conhecimento verdadeiro seria aquele com correspondência com o mundo natural, enquanto que a pós-verdade seria identificada como pertencendo somente ao polo social (crença). Com base nessa dicotomia, quem garante a distinção absoluta entre ambas é a separação natureza-sociedade.

A partir do quadro ontológico-epistemológico resumido nas figuras 1 e 2, dizse que ciência evolui aumentando o número de sentenças verdadeiras ou, pelo menos, diminuindo as afirmações falsas, como propõe Popper $(2008)^{10}$. Isso implica que, com o passar do tempo, conseguimos formar uma ideia cada vez mais clara do que seja esse mundo das coisas-em-si, através da correspondência entre teoria e mundo natural. Isso é feito pela constante depuração do subjetivo em relação ao objetivo. Dentro dessa perspectiva, defende-se que, quando o cientista trabalha em seu laboratório, ele consegue se aproximar do objeto, afastando-se da sociedade. Nesse caminho, o cientista identifica quais são os aspectos subjetivos e, portanto, não confiáveis ou falsos do conhecimento (suas crenças, suas intuições primárias), conseguindo expurgá-los. É através desse processo de purificação do laboratório que os modernos dizem separar todos os eventos em dois polos ontológicos: a natureza (a realidade objetiva) e a sociedade (a realidade subjetiva). No fim, o cientista torna-se um representante da natureza, um porta-voz dos fatos científicos, representação essa totalmente distinta da representação política, que é repleta de interesses pessoais e disputas de poder (Latour, 1993, 2013).

Tal discurso ainda implica, portanto, a noção do cientista como um profissional apolítico, desligado das questões sociais e econômicas, enclausurado em seu laboratório, próximo apenas do que é natural e não social. A boa ciência, no mundo moderno, deve libertar-se da política. Como Latour $(2013,2016)$ aponta, a obra de Gaston Bachelard $(1996)^{11}$, talvez, seja um importante exemplo de tal visão de mundo. Além disso, ao mesmo tempo em que cria noção de uma natureza livre da sociedade; tal metafísica permite a noção de uma sociedade livre da natureza. A Sociologia de Durkhein, articulada no início do século XX, é, portanto, uma consequência do discurso moderno, uma vez que propõe justamente a possibilidade de se analisar a sociedade como um campo autônomo, independente de tudo que é biológico (e, portanto, natural) (Latour, 2001). Tal visão de mundo, ademais, implica traduzir a duplicação da história do mundo (em história da natureza e história da sociedade) para a história da ciência: os historiadores passam a falar de uma história interna (dos conteúdos) e externa (das relações sociais) (Latour, 1999b) ${ }^{12}$.

Com tal visão, nós que pertencemos ao coletivo que desenvolve a Ciência

10 Para avaliar as implicações do pensamento de Popper para a Educação em Ciências, sugerimos os trabalhos de Lang (Lang, 1989, 1996) e de Lang e Ostermann (2002).

11 Para uma visão sobre a produção intelectual de Bachelard e suas implicações para Educação em Ciências, sugerimos o trabalho de Lopes (1996).

12 Para uma discussão sobre historiografia da ciência, sugerimos o trabalho de Videira (2007). Para as implicações da historiografia da ciência para a Educação em Ciências, sugerimos o livro organizado por Peduzzi, Martins e Ferreira (2012) e, em especial, para distinção entre história interna e externa o capítulo de Oliveira e Silva (2012). 
moderna, passamos a ser uma cultura privilegiada dentre tantas outras que, por não possuírem um método de purificação, misturam, a todo o momento, elementos sociais e naturais. Enquanto que os cientistas, ao irem para o laboratório, interpretam as inscrições de seus equipamentos e descobrem fatos, autônomos, independentes, elementos da natureza, outras comunidades lidam apenas com seus fetiches. Isto é, "projetam num objeto sem significado suas próprias crenças e desejos” (Latour, 2017, p. 361). Os ídolos dos outros, elementos de sua descrição da realidade, não passam de "nada a não ser telas brancas nas quais é projetado o poder da sociedade, dominação, ou o que quer que seja" (Latour, 2004b, p. 238, tradução nossa). Na própria definição de pós-verdade do Dicionário Oxford temos essa dicotomia recuperada: de um lado o fato, do outro as crenças e apelos emocionais (os fetiches). Vemos, portanto, que a ruptura original (entre natureza e sociedade), tal qual o pecado bíblico, é a fonte de todas as rupturas do discurso da ciência moderna (as quais são sumarizadas na Figura 1).

\begin{tabular}{|c|}
\hline Natureza e Sociedade \\
\hline Ontologia e Epistemologia \\
\hline Epistemologia e Política \\
\hline Matéria e Signo \\
\hline Conhecimento e Crença \\
\hline $\begin{array}{c}\text { Representação Científica e } \\
\text { Representação Política }\end{array}$ \\
\hline $\begin{array}{c}\text { Dentro da ciência e fora da } \\
\text { ciência }\end{array}$ \\
\hline "Nós" e os "outros" \\
\hline Fato e Fetiche \\
\hline Verdade e Pós-Verdade \\
\hline
\end{tabular}

Figura 1. O que o discurso cientificista quebrou

A questão levantada, então, por Latour é a seguinte: será que podemos confiar no discurso cientificista? Será que natureza e sociedade estão apartadas? Conhecimento e existência são ortogonais? Práticas epistêmicas são apolíticas e disputas políticas não são afetadas por práticas epistêmicas? A matéria está irreconciliavelmente distante dos signos? São os fatos científicos diferentes dos fetiches? É a pós-verdade tão diferente da verdade? Para responder a tais questionamentos, precisamos abandonar, momentaneamente, o discurso da ciência moderna e olhar mais de perto a prática científica - compreendendo o que os cientistas fazem e não somente aquilo que dizem fazer.

\section{Um quadro ampliado sobre a ciência: As persistentes contradições entre discurso e prática}

Em Cogitamus, Latour (2016) discute a narrativa de Plutarco sobre a história do encontro entre Arquimedes e Hierão, o rei de Siracusa. Tal história mítica é sintetizada por Latour em quatro atos. Nos três primeiros, temos o seguinte enredo: "Ato I: 
Arquimedes vai até Hierão para compartilhar com ele suas ideias mais loucas. Ato II: Hierão propõe a Arquimedes o desafio de comprovar a utilidade prática de suas ideias. Ato III: Arquimedes consegue realizar uma façanha tamanha que sozinho, defende Siracusa dos romanos" (Latour, 2016, p.23). Ou seja, Arquimedes (cientista) busca o rei (político) para oferecer seus serviços. O rei (político) é mobilizado, interessa-se por Arquimedes (cientista), e lhe desafia a ajudar na defesa contra os romanos. Arquimedes desenvolve a catapulta ("descobrindo" um princípio da natureza) e com isso altera o resultado de uma guerra entre dois povos (feito político). Na sequência, no ato 4, Plutarco afirma que Arquimedes não deixou nada escrito, pois considerava "desprovido de nobreza toda ocupação da mecânica e toda arte às necessidades da vida." (Latour, 2016, p.23). Ou seja, depois de Plutarco narrar que Arquimedes procurou um político para oferecer seus trabalhos, ele narra o cientista como um ser desprovido de interesses pela política. Nesta pequena história, três questões interessantes surgem para Latour:

Como é possível que um homem das ciências possa despertar interesse em um príncipe, visto que os domínios de ambos são completamente alheios entre si? Como é possível que esses domínios alheios sejam, contudo, suscetíveis a uma continuidade tão perfeita que possam se transformar em comensuráveis? Graças a qual terceiro milagre, ainda que se encontrem perfeitamente unidos, eles são apresentados como absolutamente incomensuráveis? (Latour, 2016, p.25)

Parece haver algo de contraditório, portanto, entre a prática científica e o que se fala sobre ela no que tange aos interesses políticos. Além disso, quando Latour investigou a prática de cientistas em um laboratório (Latour, \& Woolgar, 1986), ele percebeu que os cientistas não lidam com fatos objetivos (como eles afirmam fazer). Pelo contrário, como Bachelard já havia apontado, a realidade científica mobiliza equipamentos e teorias, demanda uma "fenomenotécnica". Os cientistas afirmam descobrirem fatos (verdades); mas, quando interpretam o sinal de um aparelho de caracterização de materiais, por exemplo, o que eles fazem é projetar sobre a inscrição seu conhecimento teórico (os dados não falam por si mesmos). Tal noção de projeção, entretanto, está próxima da definição de fetiche. Se os dados precisam ser interpretados, não há fatos sem alguma dimensão de fetiche. E, portanto, parece que há um je ne sais quoi de pós-verdade na verdade científica. Apresentamos, na sequência, algumas reflexões sobre como as principais críticas à Ciência, com “C” maiúsculo, abordam essa questão e, na próxima seção, discutimos a interpretação do próprio Latour.

\section{Críticas à Ciência "com C maiúsculo": Sociologia dos Cientistas, Programa Forte da Sociologia, Vertente Semiótica}

Existem diferentes críticas à visão de Ciência com $\mathrm{C}$ maiúsculo (o que chamamos de discurso cientificista). Em especial, Latour menciona três grupos distintos de crítica. Apesar de todos eles se oporem à suposta objetividade e neutralidade científica, suas visões metafísicas diferem entre si e diferem com relação à proposta de Latour. 


\section{a) Sociologia dos Cientistas}

O início da área de Sociologia da Ciência é marcado, como aponta Latour e Woolgar (1986), por uma "Sociologia dos Cientistas", isto é, por uma área preocupada apenas com as relações humanas entre si. Tal tendência, portanto, ainda que critique a neutralidade da ciência, visto que explicita as disputas de poder existentes na comunidade científica, adere ao contrato modernista, uma vez que mantém sociedade e natureza apartadas. Cabe à Sociologia da Ciência, nessa perspectiva, explicar apenas o que é "social" (no sentido durkheiniano), deixando o conteúdo da ciência (a natureza) fora de tal explicação. Seguindo os comentários de Latour e Woolgar (1997), podemos mencionar como exemplo, os trabalhos sobre concorrência entre pesquisadores (Bourdieu, 1976; Lemaine, \& Matalon, 1969), sobre a evolução das disciplinas (Lemaine et al. 1976), ou sobre sua psicologia (Mitroff, 1974).

Nesta proposta sociológica, além de manter a natureza livre de qualquer discussão política, adere-se, também, à noção durkheiniana de uma dimensão social reificada (macroscópica) influenciando as ações dos cientistas e dos laboratórios (escala microscópica) - o que Latour chama de Sociologia 2D (Latour et al., 2012). Pierre Bourdieu (1997), por exemplo, define a noção de campo, "o universo no qual estão inseridos os agentes e as instituições que produzem, reproduzem ou difundem a arte, a literatura ou a ciência. Esse universo é um mundo social como os outros, mas que obedece leis sociais mais ou menos específicas." (Bourdieu, 1997, p.20) ${ }^{13}$. Ou seja, define-se o campo (escala macro) que afeta as atuações dos cientistas (escala micro) - na dimensão puramente humana. A natureza não participa de tal discussão. Defendemos que a contribuição de tal proposta sociológica é inegável para o enfraquecimento da visão de ciência com C maiúsculo, uma vez que explicita o caráter politizado da prática científica. Entretanto, ela é limitada por nada falar sobre a "natureza", o conteúdo da ciência (Latour et al., 2012).

\section{b) O Programa Forte da Sociologia}

A explicação dos modernos sobre o conhecimento, conforme discutimos, é assimétrica, pois reconhece a natureza como fonte do conhecimento verdadeiro (os fatos), enquanto que à sociedade cabe apenas a produção de crenças (os fetiches). Enquanto que a Sociologia dos Cientistas não interfere nesse acordo modernista, circunscrevendo-se a falar dos homens entre os homens, o Programa Forte da Sociologia (PFS) ${ }^{14}$ ataca o coração do discurso cientificista. David Bloor (1991) define seus quatro princípios 1) Causalidade, isto é, o PFS deve explicar conhecimento e crença; 2) imparcialidade, isto é, o PFS não distingue entre racionalidade e irracionalidade, verdade e falsidade, sucesso ou fracasso; 3) Simetria, isto é as mesmas causas que explicam a verdade explicam a

13 Existem, hoje, propostas do uso de elementos da Sociologia da Ciência de Bourdieu na Educação em Ciências (Lima, Pinheiro, \& Ostermann, 2012).

14 Podemos mencionar, como exemplo de trabalhos em Educação em Ciências que dialogam com o PFS, a proposta de Bagdonas, Zanetic e Gurgel (2014). 
falsidade e 4) Reflexividade, isto é, o PFS deve explicar a si mesmo.

No PFS, não mais se busca uma sociologia dos cientistas, mas uma sociologia do conhecimento científico, daquilo sobre o qual os cientistas falam. O princípio da causalidade (1) indica que o PFS busca, assim como na sociologia durkheiniana, explicações causais, isto é, aquilo que causa crença e conhecimento. E, nesse sentido, a sociedade se torna a fonte da explicação de todo conhecimento verdadeiro ou falso. Os princípios da imparcialidade (2) e da simetria (3) tornam o PFS uma proposta relativista, na medida em que impossibilitam distinguir verdade e falsidade. Nesse sentido, o PFS representa mais um forte ataque à Ciência com $\mathrm{C}$ maiúsculo, reduzindo seus conteúdos a uma construção social e retirando-lhe qualquer traço de objetividade. Por tomar a sociedade como causa de todo conhecimento verdadeiro ou falso, tal vertente da Sociologia da Ciência pode ser interpretada como um dos suportes do cenário de pósverdade, como apontou Latour (2004).

Deve-se notar, por fim, que o PFS é "construtivista para a natureza, e realista para sociedade" (Latour, 2013, p. 95) ${ }^{15}$. Ou seja, a simetria explicativa do PFS sustenta uma assimetria ontológica - reificando a sociedade como um polo autônomo.

\section{c) Vertente Semiótica e Pós-Moderniade}

A terceira possibilidade adotada pela crítica foi dissolver os dois polos ontológicos no discurso: nem natureza nem sociedade explicam nada. Estamos, eternamente, presos aos jogos da linguagem. Latour explica: "Infelizmente, a triste história não acaba aqui. Por mais incrível que pareça, é possível avançar ainda mais na senda errada, (...). Sim, nós perdemos o mundo. Sim, ficaremos para sempre prisioneiros da linguagem. Não, nunca recuperaremos a certeza." (Latour, 2017, p. 21). O que Latour chama de vertente semiótica, ou Império dos Signos ${ }^{16}$, assim, refere-se às perspectivas teóricas normalmente apresentadas no contexto do pós-estruturalismo, que reduzem a realidade à sua dimensão discursiva: sujeito e natureza se tornam artefatos do discurso. Diferentes perspectivas aderem (sob diferentes aspectos) a tal visão. Além de Derrida (1997), principal nome mencionado por Latour como representante da vertente semiótica, pode-se ainda mencionar trabalhos de Eco (1981), Greimas (Greimas, \& Courtés, 1982.), Pêcheux (1997) e Laclau (2014) ${ }^{17}$. De acordo com Mcintyre (2018), ao reduzir a realidade a efeitos do discurso, o pós-modernismo abriu o caminho para o desenvolvimento da pós-verdade. Paul Feyerabend (2010), considerado um dos grandes pensadores do relativismo, em uma nota de rodapé na introdução da segunda edição de Contra o Método, menciona que, frente aos avanços de algumas perspectivas, como a do pós-modernismo, ele passou a crer que se deveria dar mais ênfase à razão.

15 A interpretação de Latour é contestada por David Bloor e seu antagonismo é público (Bloor, 1999; Latour, 1999a).

16 Provavelmente em menção ao livro homônimo de Roland Barther (1982).

$17 \mathrm{Na}$ Educação, encontra-se o texto de Alice Lopes e Elizabeth Macedo (2011) que se alinha a tal noção. Para uma visão geral sobre os diferentes “pós”, sugerimos o texto de Alice Lopes (2013). 


\section{Uma Metafísica Alternativa: do Primado da Ontologia para o Primado da Ecologia}

De um lado, temos o discurso da ciência e todas as dicotomias que ele cria (Figura 1), do outro, temos a prática científica e as narrativas sobre ela elaboradas pela Sociologia dos Cientistas, PFS e Vertente Semiótica. Como lidar com o embate entre tais visões? Ao invés de "tomar partido" e decidir o que é verdadeiro, a versão do cientista apolítico ou do cientista politizado, a versão dos fatos ou dos fetiches, Latour propõe tomar a própria contradição como objeto de estudo, isto é, não tentar resolver a contradição, mas tentar, antes de tudo, entender como que essa contradição é possível, o que acontece para que ela possa existir. Ao invés de perguntar se os hormônios descobertos em um laboratório existem ou não, ou se o "bom" cientista engaja-se em relações de poder ou não, devemos perguntar como é possível produzir 'coisas' no laboratório e, depois, têlas como autônomas, como é possível a ciência interferir na política (e vice-versa) e depois parecer que política e ciência são domínios distantes. Para tentar entender isso não é suficiente usar o raciocínio apodítico, lançando mão de teorizações a priori, nem confiar na narrativa dos cientistas, pois eles são "informantes privilegiados, mas sempre informantes de quem se duvida” (Latour, \& Woolgar, 1997, p.20).

O caminho que Latour apresenta é o de estudar a ciência em ação, durante seu desenvolvimento, a que está sendo feita, com todas as suas controvérsias. Isso é o que Latour e Woolgar (1997) fazem na obra A Vida de Laboratório: A Produção dos fatos científicos, inaugurando o que se chama de "Antropologia do Laboratório", ou "segunda onda CTS" (Mody, 2015), marcando, juntamente com o desenvolvimento da discussão ontológica que será apresentada adiante (Harman, 2009), a entrada da Antropologia nos laboratórios científicos e de engenharia. Latour é o pioneiro de tal área juntamente com outros grandes nomes da Sociologia da Ciência (Knor-Cetina, 1981; Lynch, 1985) ${ }^{18}$. Deve-se notar que tal movimento rompe com a busca de uma sociologia macroscópica da ciência e passa a se preocupar com casos específicos, como em uma microssociologia da ciência. Pode-se entender que essa mudança de um olhar macro para um olhar micro marcou também perspectivas historiográficas, como no caso da História Cultural da Ciência (Lightman, 2016), para a qual o estudo das práticas científicas é fundamental para a compreensão de como as ciências se constituíram ao longo da História ${ }^{19}$. No caso da Educação em Ciências, muitos estudos são fortemente influenciados pela Antropologia de Laboratório, em especial pela obra seminal de Latour (Queiroz, \& Almeida, 2004; Rezzadori, \& Oliveria, 2011; Roxael, Diniz, \& Oliveira, 2015; Vianna, \& Carvalho, 2001a). Tais trabalhos discutem as implicações, para educação científica, do fato de que as ciências são muito maiores do que os conteúdos que elas produzem.

É importante destacar que o estudo etnográfico não é o único método de

18 Para uma visão geral sobre o início da área de Antropologia de Laboratório, sugerimos o trabalho de Woolgar (1982).

19 Existem propostas em Educação em Ciências que já discutem as implicações da História Cultural da Ciência para Educação em Ciências (Moura, \& Guerra, 2016). 
estudo empregado por Latour. Ao contrário, uma de suas obras mais importantes, $A$ Pasteurização da França (Latour, 1988b) é um estudo historiográfico no qual os escritos de Pasteur são analisados. Essa obra é considerada uma das fundadoras da Teoria AtorRede (Latour, 2005) juntamente com as obras de Callon (1984) e Law (1984) ${ }^{20}$.

Ao elaborar sua proposta, Latour não o faz em um vazio discursivo, mas pronunciase fazendo oposição explícita a todas as visões da Sociologia da Ciência anteriormente apresentadas. Em Jamais Fomos Modernos, Latour comenta:

"Mas então é política? Vocês reduzem a verdade científica a interesses e a eficácia técnica a manobras políticas?” Eis aí o segundo mal-entendido. Se os fatos não ocuparem o lugar ao mesmo tempo marginal e sagrado que nossas adorações reservam para eles, imediatamente são reduzidos a meras contingências locais e míseras negociatas. (...) "Mas se vocês não falam nem das coisas-em-si nem dos humanos-entre-eles, quer dizer que vocês falam apenas do discurso, da representação, da linguagem, dos textos. Esse é o terceiro mal-entendido, (...) quando descrevo a invenção-descoberta dos peptídeos do cérebro, falo realmente dos peptídeos em si, e não de sua representação no laboratório do professor Guillemin. É verdade, entretanto, que se trata de retórica, estratégia textual, escrita, contextualização e semiótica, mas de uma nova forma que se conecta ao mesmo tempo à natureza e ao contexto social sem, contudo, reduzir-se nem a uma coisa nem a outra. (Latour, 2013, p. 10)

No trecho transcrito, Latour destaca que ele não fala da representação do peptídeo (mundo da linguagem na Figura 2), mas fala realmente dos peptídeos em si, sem que eles deixem, entretanto, de possuírem também uma dimensão retórica e social. Ou seja, para Latour, a realidade é natural, mas não é só natural, é social, mas não é só social, é discursiva, mas não é só discursiva. Para entender como isso é possível dentro de um quadro metafísico consistente, Latour articula diferentes estudos empíricos e discussões filosóficas em torno de uma visão de mundo monadal, a qual apresentamos na próxima seção.

\section{Fermentação, Ácido Lático, Pasteur e mais Filosofia: como a fabricação de fatos os torna autônomos.}

Como já foi comentado, Latour se afasta da Sociologia 2D para analisar as práticas de laboratório ${ }^{21}$. O seu objetivo, como dissemos, não é resolver a oposição entre discurso e prática, mas entender como a contradição entre eles pode existir de forma tão natural, como é possível que, apesar de construídos, os fatos científicos pareçam tão autônomos e independentes de qualquer criação. Para isso, tomamos o exemplo das análises de Latour sobre Pasteur (Latour, 1983, 1988b, 1999c, 1999b), cujos trabalhos evidenciaram que a fermentação possuía causas biológicas e não puramente químicas, como assumia a visão hegemônica da época.

20 A Teoria Ator-Rede (TAR) será discutida na sequência do texto bem como os trabalhos de pesquisa em Educação em Ciências que a usam.

21 Latour sofre críticas por parte dos sociólogos da ciência, pois, ao fazer isso, estaria perdendo a dimensão social, que só aparece na escala macro (na sociedade e não no laboratório) (Lorenzi \& Andrade, 2011; Schinkel, 2007). 
Para propor a existência do ácido lático, Pasteur precisou da mediação do que Latour chama de "testes de laboratório". Em tais testes, uma certa amostra que se quer caracterizar é submetida a um aparelho, como um microscópio, que produz um certo resultado, uma inscrição ${ }^{22}$. Tal inscrição é o resultado ou a performance do sistema amostra + aparelho. Desta forma, ao fim de um teste de laboratório tudo que temos é:

\section{Teste 1: Amostra + Inscritor $\rightarrow$ Inscrição $_{1}$}

Podemos repetir esse procedimento n vezes:

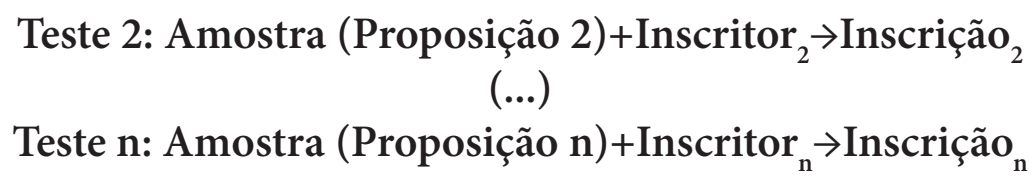

Ao final, temos um conjunto de $n$ inscrições que se referem aos sistemas amostrainscritores. Nada disso é o ácido lático, o fato a ser descoberto. Pasteur precisa, ainda, interpretar tais inscrições à luz de teorias vigentes, atribuindo-lhe significado físico. Neste momento, as inscrições (meros elementos semióticos) tornam-se performances daquele sistema no mundo real, isto é, passam a descrever como que algo do mundo se comporta. Para que o ácido lático possa existir, entretanto, é necessário ainda mais um elemento: o cientista precisa o associar a $n$ performances, interpretando que elas, conjuntamente, são consistentes com a existência de algo novo e singular - o ácido lático.

$\mathrm{O}$ ácido lático, em nenhum momento foi acessado diretamente, mas apenas suas performances. Tais performances, entretanto, são resultantes da articulação da rede inteira: da amostra, dos equipamentos, e das interpretações dadas por Pasteur a partir de outras teorias. Elas não estavam prontas, dadas, no polo ontológico da natureza, esperando para serem desveladas. O termo ácido lático passa a ser o rótulo que esconde a rede. Ele não pode existir se Pasteur não projetar sobre a rede tal rótulo. A descoberta do fato, na verdade, envolve sempre uma dimensão fetichista (Latour, 2017). Mas isso não diminui em nada a validade do que foi articulado. Quanto mais bem construído for o fato no laboratório, isto é, quão mais extensa e confiável for a rede que articula um fato, mais "real" ele se torna, da mesma forma que quanto mais bem articulado for um fetiche, melhor é o efeito que ele causa sobre as pessoas com relação ao que é esperado dele ( Latour, 2004b). A semelhança entre as duas palavras não é casual e, na verdade, ambas possuem a mesma etimologia, fatos e fetiches são dois lados do mesmo fenômeno. Por isso, Latour sugere abolir tal dicotomia em prol de um único termo, fatiche (Latour, 2004b, 2017).

Não podemos pensar, portanto, que o ácido lático é algo do mundo natural, social,

22 "termo geral referente a todos os tipos de transformações que materializam uma entidade num signo, num arquivo, num documento, num pedaço de papel, num traço" (Latour, 2017, p. 362). Para uma análise sobre o papel de inscrições na Educação em Ciências, sugerimos os trabalhos de Roth e Tobin (1997) e Oliveira (2010). 
ou linguístico puramente, mas um híbrido de natureza, linguagem e sociedade. Aliás, em todo momento, tudo com que Pasteur lidou foram híbridos. Mesmo a primeira amostra selecionada já não é uma amostra puramente natural, visto que ela foi escolhida entre todos os possíveis corpos do Universo por motivos pré-estabelecidos, ou seja, ela já significa algo no discurso. Da mesma forma, os equipamentos usados não são matéria simplesmente, visto que também participam de uma cadeia discursiva, sendo construído a partir de teorias e permitindo a produção de performances que, também, "querem dizer" algo 23.

Suponhamos, agora, que se descobre que o aparelho usado para o teste 1 estava contaminado, o aparelho do teste 2 estava descalibrado, a teoria usada para interpretar o teste 3 foi invalidada por outra descoberta e assim sucessivamente. Aos poucos, o ácido lático, tão real, perde toda sua existência. O que garante a existência do ácido lático não é ele mesmo (como os objetos-em-si), mas a rede que é mobilizada para sua existência. Se a rede for desarticulada, o ácido lático deixa de existir.

A visão de Latour pode ser rotulada, portanto, como não-essencialista. Isto é, ele não parte da noção de que existe uma essência na natureza prestes a ser descoberta (Lima, Ostermann, \& Cavalcanti, 2018a). Os atores (ou actantes) ${ }^{24}$ são construídos pela articulação com outros actantes. A natureza não precisa ser entendida como um jogo de soma zero, isto é, não precisamos nos limitar à pobreza de um mundo de coisas-emsi com um número finito de objetos para serem descobertos. A realidade é muito mais complexa do que isso, e as ciências produzem proposições muito mais complexas do que a afirmação de que um cachorro está na porta.

Tal visão ontológica pode ser explicada em termos da Filosofia das Proposições de Whitehead (1978). Proposições ${ }^{25}$ não são sentenças, são actantes (ou atores) e sua única propriedade a priori é que existem por meio da articulação entre elas (Latour, 1999b). Ou seja, estamos lidando com uma metafísica que não coloca a existência no ente em si e, portanto, rompe com a ontologia (conforme definição da nota de rodapé 5). A existência é dada pelas relações de associação com outros entes. Trata-se de uma metafísica relacional, o que Latour denomina de ecologia (Latour, 2001).

Assim, por exemplo, a "descoberta do ácido lático" envolve a articulação do ácido lático por diferentes proposições, como Pasteur e o fermento. Pasteur (humano) e o fermento (não-humano) se articulam, mobilizando o ácido lático (Latour, 1999b).

23 Para mais referência sobre a hibridização entre matéria e signos, sugerimos o capítulo 2 de Esperança de Pandora ( Latour, 2017) e o artigo Berlin Key or how to do words with things (Latour, 2000).

24 "Em vez de começar com entidades que já compõem o mundo, os estudos científicos enfatizam a natureza complexa e controvertida do que seja, para um ator chegar a existência. O segredo é definir o ator com base naquilo que ele faz- seus desempenhos- no quadro dos testes de laboratório." (Latour, 2017, p. 358). No caso apresentado, a amostra, Pasteur, os equipamentos e as teorias são todos actantes que se articulam gerando um novo actante, o ácido lático. Observa-se que humanos e não humanos passam a ser tratados simetricamente, todos são actantes que se articulam com outros actantes, gerando performances. Nesse sentido, não se pode mais pensar em uma sociedade de humanos entre eles apenas. Os não-humanos fazem parte dessa sociedade. Por outro lado, não se pode pensar em uma natureza totalmente livre de aspectos sociais. Ademais, Strum e Latour (1987) e Latour (1996) alertam para o fato de que mesmo na "Natureza" já se pode encontrar aquilo que denominamos interações sociais. 25 O termo proposição, assim como actante, pode ser usado para desginar elementos que, na visão moderna, são classificados como objetos da natureza, da sociedade ou do discurso. 
Antes dessa articulação, não havia o ácido lático, depois dela há. Não se pode, também, pensar que Pasteur usou o fermento para articular o ácido lático, como se só o humano tivesse participação no processo, pois, os não-humanos resistem à vontade humana modificando as performances da rede (Callon, 1984; Latour, 1988b).

Ademais, se parar de ser articulado, o ácido lático deixa de existir (Latour, 1999b). Para se poder fazer fermentação com ácido lático é necessário que todo uma rede laboratorial seja construída. Se, hoje, perdêssemos todo o conhecimento de práticas laboratoriais que temos, é possível que a tese do surgimento espontâneo voltasse a circular entre nós (Latour, 1999b). O número de atores que compõem a realidade, portanto, muda com avanço da prática científica, a qual pode criar novos atores e destruir antigos. É a materialidade de tal rede, como a rede de laboratórios, que garante a sua existência. A natureza não é algo que sempre existiu e para sempre existirá. Ela é tão repleta de historicidade quanto a própria humanidade. Não precisamos mais pensar que a natureza é algo independente, que existe "lá", esperando para ser descoberta. A "natureza" é aquilo que articulamos.

É mediante a articulação de diferentes proposições (inscritores, teorias, cientistas) que o actante pode "aparecer". Sua existência depende da rede que o articula. Quanto mais proposições forem articuladas, maior será a existência de tal proposição ${ }^{26}$. E, com isso, resolvemos o problema da contradição entre discurso e prática da ciência: os fatiches, quanto mais bem articulados forem, mais autônomos se tornam, mais livres da mediação humana, e, portanto, mais factuais. Quanto mais construirmos um fatiche, mais parecido com um fato ele se torna. Então, tanto a prática científica quanto o discurso estão corretos. Sim, os cientistas fabricam verdades no laboratório. Mas, também, sim, tais verdades se tornam autônomas.

Isso traz uma consequência direta sobre a dicotomia fato e crença, presente na definição de pós-verdade. Uma vez que não existe mais um mundo natural, objetivo, apartado, como fonte de verdade, não temos como diferenciar fato de crença. Entretanto, como proposições existem mediante a articulação com outras proposições, podemos dizer que cada proposição tem um intervalo ou envelope espaço-temporal de validade (identificada pela rede utilizada para articular aquela proposição). Quanto mais proposições forem articuladas a uma proposição, maior será seu envelope espaçotemporal de validade.

Um cientista em um laboratório, por exemplo, quer afirmar a existência de um hormônio. Se ele simplesmente fizer isso, o hormônio, enquanto proposição, não terá um envelope espaço-temporal de validade significativo. Se, por outro lado, o cientista for capaz de produzir diversas inscrições, fazendo suas interpretações à luz de teorias fortes e com credibilidade, o hormônio será uma proposição altamente articulada e, portanto, com um envelope espaço temporal de validade muito maior. O envelope espaço

26 Existência não é mais uma propriedade binária (existe ou não existe), mas corresponde a um espectro de possibilidades. Existência é uma propriedade relativa. Existir é existir para a rede. E, mais, os não-humanos conquistam o direito de ter historicidade como os humanos visto que sua essência também está em constante processo de estabilização. 
temporal de validade do actante articulado se estende pela rede dos $n$ testes realizados. Se mais testes forem feitos no sentido de articular a existência de tal actante, maior será seu envelope. Se, por outro lado, os testes forem sendo desarticulados, o actante terá seu envelope reduzido.

Um moderno diria que o cientista descobriu o hormônio (um fato) e que esse sempre esteve lá; Latour diria que o hormônio (um fatiche) foi articulado por teorias e experimentos. Quanto mais proposições forem usadas, ou seja, mais construído o hormônio for, mais "real" ele será. E, por isso, a construção é que permite a realidade dos objetos científicos bem como a "veracidade" de uma afirmação - ontologia e epistemologia são fundidos em uma só visão (Latour, 1999b).

Então, a diferença entre o que os modernos chamam de fato e de fetiche (ou conhecimento e crença, verdade e pós-verdade) não é que um corresponde ao mundo real e o outro não; ambos são fatiches, mas possuem envelopes espaço-temporais diferentes. Apesar dessa simetria parecer implicar um alto grau de relativismo, visto que reforça o caráter local e temporário de toda proposição, ela nos permite "classificar" as proposições (não porque umas são verdadeiras e outras são falsas) em termos de sua articulação: proposições mais bem articuladas tem maior envelope de validade espaçotemporal.

Podemos usar um exemplo para entender isso: um epistemólogo absolutista diria que o modelo de Terra plana é falso enquanto que o modelo de Terra redonda éverdadeiro. Latour percebe esse exemplo de uma forma mais complexa do que tal dicotomia. Terra plana é uma proposição, e como tal, se articula com outras proposições, como textos religiosos, e alguns experimentos aliados a concepções pré-newtonianas. Terra redonda, por sua vez, é uma proposição e, como tal, se articula com outras proposições, como dados empíricos e experimentos associados a concepções newtonianas. A diferença entre elas se marca quando percebemos que o número de proposições capazes de serem mobilizadas pelo segundo modelo é muito maior do que o primeiro e, portanto, a Terra redonda tem um envelope espaço temporal de validade muito maior e mais significativo do que o de Terra plana. Enquanto a afirmação de que a Terra é plana pode se sustentar por alguns metros, a afirmação de que a Terra é redonda pode ser articulada em um espaço bem maior. Apesar disso, a noção de uma Terra redonda também não é universal, tendo um limite de validade, pois não se articula com dados de relevo e de achatamento da Terra, por exemplo.

Deve-se ressaltar que tal rede é articulada por humanos e não-humanos, dependendo, também, de relações econômicas e políticas. Assim, Latour descreve simetricamente, por exemplo, como Elliot, ao desenvolver um programa de energia nuclear, mobilizou os nêutrons ("natureza") dentro do laboratório e o Ministério da Defesa ("sociedade") fora do laboratório para atingir seus objetivos, isto é, Latour mostra como objetivos científicos são traduzidos em objetivos políticos e vice-versa (Latour, 1999b) em um emaranhado de relações complexas e difusas que não se restringem ao espaço e aos atores do laboratório. 
Para explicar essas relações, Latour faz uma descrição da atividade científica usando um modelo de sistema circulatório. Para ele, existem 5 processos que formam a prática cientifica (Latour, 1999b). O primeiro é a mobilização do mundo, que envolve a prática de laboratório (entendida aqui como a mobilização de diferentes actantes ou a articulação de diferentes proposições). O segundo é a autonomização, isto é, a busca de colegas que trabalhem em problemas próximos e que permita a sustentação de uma área de pesquisa. $\mathrm{O}$ terceiro é a criação de alianças que permitam o financiamento e desenvolvimento da pesquisa. O quarto é a representação pública, que trata de levar e validar a prática científica perante a sociedade. Por fim, o quinto elo são os nós e elos entre todos os processos. É o conjunto de todo esse sistema, que envolve atores das mais diversas áreas da sociedade, que caracteriza a prática científica, a qual está representada na Figura 3.

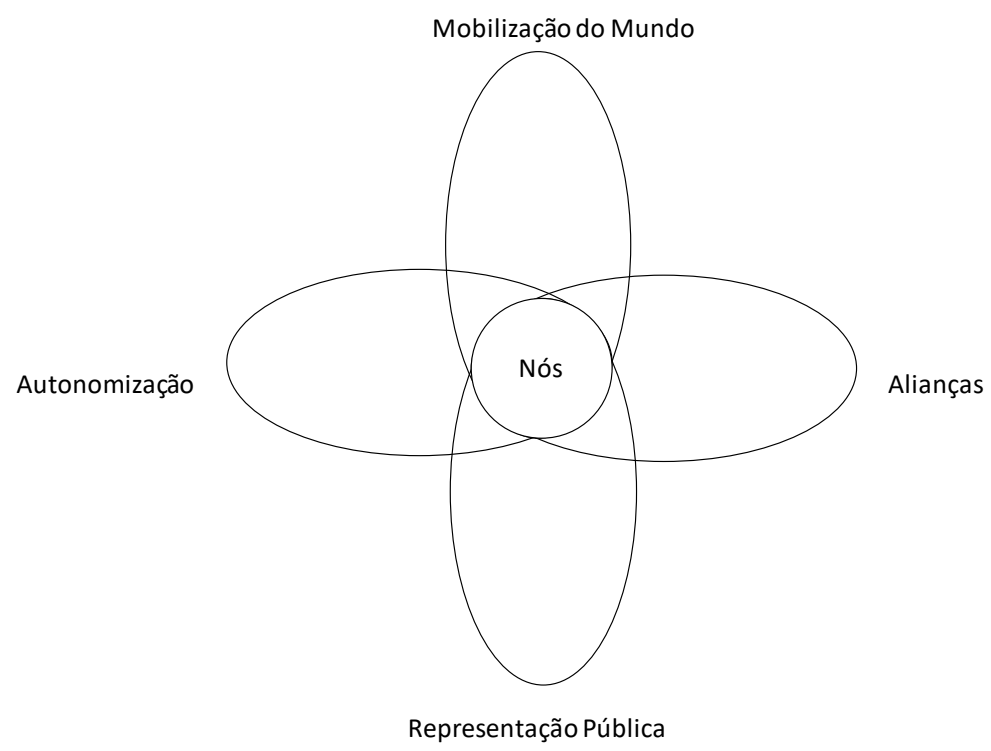

Figura 3. Sistema Circulatório da Ciência. Adaptado de Latour (1999b)

Tal descrição resulta, portanto, em mais uma consequência epistemológica: não existem interior e exterior da ciência. Quando chegamos perto da ciência em ação, percebemos que atores de todas as esferas da sociedade são mobilizados para que a prática científica possa ocorrer. E isso resolve mais uma contradição apresentada entre discurso e prática científica. Para um fato ser autonomizado ele precisa mobilizar toda a sociedade e, portanto, se hibridiza com questões políticas. Entretanto, quanto mais "bem feito" for o trabalho político, mais articulado se torna aquele fato e, portanto, mais autônomo, parecendo livre de qualquer política. Para que um fato possa se "livrar" do seu lado social ele precisa, primeiramente, se articular com a sociedade. As duas visões, a do cientista politizado e do não-politizado são consistentes apesar de parecem contraditórias. A política e a criação dos fatos, portanto, não diminuem a validade da ciência, são justamente o que a garante.

Estamos, finalmente, em condição de colocar o debate sobre pós-verdade em uma 
nova perspectiva, e, assim, redefinir o significado dado pelo dicionário Oxford. Quando um grupo apresenta uma visão alternativa à da ciência, não estamos lidando com uma oposição entre verdade e falsidade ou conhecimento e crença ou fato e fetiche. Estamos lidando com uma concorrência entre proposições. A proposição científica articula sua rede de proposições e a do grupo alternativo também. Isso acontece a todo momento dentro da própria ciência e é um processo legítimo. $\mathrm{O}$ que podemos chamar de pósverdade, entretanto, são as proposições que, apesar de muito menos articuladas que as proposições científicas, são divulgadas como equipolentes ou superioras a elas ${ }^{27}$. No caso do aquecimento global, por exemplo, grupos financiados por setores interessados economicamente no assunto sustentam sua proposição como se ela fosse equiparável aos resultados obtidos por toda comunidade, tentando impor uma falsa controvérsia. Apesar de não lidar com uma verdade absoluta, a partir da metafísica apresentada, é possível decidir por adotar medidas que diminuam o impacto da ação humana no efeito estufa visto que é possível constatar que a rede científica possui um envelope de validade espaço-temporal maior (articula mais proposições) do que a visão antagônica.

\section{o Coletivo: uma sociedade de humanos e não-humanos}

Para concluir a discussão sobre a visão metafísica de Latour, ressaltamos, por motivos de completude, o fato de que ele rompe não só com a epistemologia moderna, mas também com a sociologia moderna. Até este momento, discutimos como a visão simétrica de Bruno Latour exige uma revisão profunda dos conceitos sobre a natureza, verdade e fato. Deve-se ter em mente que sua visão simétrica exige, também, uma reformulação de nossa visão sobre a sociedade (Latour, 2013). Parte das críticas sobre Latour se refere justamente à sua ruptura com a visão hegemônica da sociologia.

Ao adotar a Filosofia das Proposições (Latour, 1999b) ou a Sociologia Simétrica (Latour, 1999b, 2013), natureza e sociedade não são mais os polos ontológicos que servem de fonte de explicação. Pelo contrário, elas são aquilo que será construído e explicado de forma contingente e temporária (Latour, 2013). Ao fim de um processo científico, a natureza e a sociedade serão construídas, serão estabilizadas, não podendo ser a fonte da explicação.

A noção de que existe uma realidade social, um contexto social e uma força social, que não podem ser reduzidos a outros campos é uma suposição a priori da visão hegemônica da sociologia moderna (como na Sociologia de Durkhein) contra a qual Latour se opõe (Latour, 2005). Assim, por motivos bem distintos, Latour concorda com

27 Não estamos defendendo que toda vez que um grupo alternativo à ciência se pronuncia, a versão mais articulada é a da ciência. Isso deve ser considerado caso a caso. Uma vez que na metafísica ecológica não há distinção entre fato e fetiche, em cada caso deve-se investigar o envelope espaço-temporal de validade de uma proposição. Há casos em que, possivelmente, a proposta dos especialistas podem ser contrariadas por uma população uma vez que a rede é social e técnica e, portanto, nem sempre as soluções encontradas dependem somente de fatores epistêmicos. Deve-se notar, por fim, que a validade de uma proposição frente à outra é sempre contingente espacialmente (dependendo da extensão da rede) e variável no tempo; podendo a proposição, hoje, "mais real" ser, no futuro, desarticulada. As escolhas sociotécnicas, neste sentido, são sempre provisórias e devem sempre estar sob suspeição. 
a frase de Margareth Tatcher: "There is no such a thing as a Society" (Latour, 2005, p. 5). Mantendo-se fiel à sua visão ontológica-epistemológica, Latour (2005) propõe uma mudança no significado de Sociologia, de Ciência da Sociedade para Rastreamento de Associações. O objetivo da Sociologia deve ser rastrear as associações existentes entre os diferentes atores que compõe uma rede e não buscar explicações sociológicas. Deve-se observar, entretanto, que, diferentemente da Sociologia de Durkheim, em que há duas escalas sociais (o indivíduo e a sociedade), a rede não está em uma escala social diferente da escala do ator, ela está no mesmo "nível", apenas desdobrada de uma forma diferente (Latour et al., 2012). Tal pressuposto significa também trazer para dentro da sociologia todos os tipos de conexões, de ligações químicas a restrições jurídicas (Latour, 2005). Dessa forma, entendemos que os coletivos de humanos e não-humanos compõem um conjunto de atores heterogêneos que interagem entre si. É esse conjunto e suas associações que se tornam o objeto de análise dessa sociologia expandida. Com isso em mente é que Latour (Latour, 1988b), Callon (Callon, 1986) e Law (Law, 1986) propõem a Teoria Ator-Rede (TAR), inspirados na sociologia de Gabriel Tarde (1999).

Adotando a terminologia de Tarde (2007), os atores são entendidos como mônadas de Leibiniz (Latour et al., 2012), ou seja, os atores não interagem em uma rede, eles são definidos pela rede (Latour et al., 2012):

Digamos que acabamos de dizer que 'Hervé C.' é agora 'professor de economia na Escola de Administração de Paris'. No início da pesquisa, não é mais do que um nome próprio. Então, nós descobrimos que ele tem um "PhD da Penn University", "escreveu sobre os padrões de votação entre os detentores de participação corporativa", "demonstrou um teorema sobre a irracionalidade da agregação", etc. Se prosseguirmos através da lista de atributos, a definição se expandirá até que paradoxalmente irá se limitar a uma instância cada vez mais particular. Muito rapidamente, assim como no jogo infantil de Q e A, nós iremos zerar com apenas um nome para a única solução: 'Hervé C. Quem é esse ator? Resposta: esta rede. O que, no início, era uma série de palavras sem sentido, sem conteúdo, um mero ponto, agora possui um conteúdo, um interior, ou seja, uma rede resumida por um nome próprio completamente especificado. $\mathrm{O}$ conjunto de atributos - a rede - agora pode ser entendido como um envelope - o ator - que encapsula seu conteúdo em uma notação abreviada (Latour et al., 2012, p. 592, tradução nossa).

Assim, a Teoria Ator-Rede propõe uma visão de como os atores devem ser entendidos. Não existem atores e suas redes: atores são redes. Aquilo que é visto como um ator a uma certa distância, se torna uma rede quando nos aproximamos. Dessa forma, o ator não é um ente fixo, rígido, com uma essência pré-existente e com propriedades autônomas; mas algo provisório, construído, que demanda esforço para ser estabilizado e para continuar existindo, exatamente, como as proposições de Whitehead. Uma proposição só existe mediante a articulação com outras proposições da mesma forma que um ator só existe mediante a associação com outros atores. 
Em termos de reflexão sobre a Educação em Ciências ${ }^{28}$, é importante ressaltar que Latour desenvolveu uma versão didática da TAR, que ficou conhecida como Cartografia das Controvérsias (Venturini, 2010), a qual pode ser resumida em apenas uma indicação: "apenas observe e descreva as controvérsias" (Venturini, 2010). Longe de estar associada com a visão da observação não mediada, a cartografia das controvérsias propõe justamente o contrário:

Privado da proteção de conceitos e protocolos, a observação não é mais pura. Pelo contrário, abre-se a todos os tipos de interferências e impurezas. Longe de ser uma substância clara destilada do caos coletivo, o conhecimento científico é o resultado de tantas contaminações quanto possível. Tal é a lição de "apenas": os dispositivos de observação são mais valiosos, quanto mais eles deixam que aqueles que são observados interfiram com aqueles que observam (Venturini, 2010, p. 60, tradução nossa).

Tal proposta pode ser ainda desdobrada em três indicações: (1) não restrinja sua observação a uma única teoria ou metodologia, (2) observe o maior número de pontos de vista possível e (3) escute as vozes dos atores mais do que suas suposições teóricas. A complexidade e a quantidade de dados que uma cartografia das controvérsias ou a TAR podem demandar tornam-nas propícias para serem exploradas valendo-se de recursos digitais (Venturini, 2012; Latour et al., 2012).

\section{Reflexões sobre Metafísica, Pós-Verdade e Educação em Ciências}

A partir do que foi discutido estamos em condições de explicar como a pósverdade, aqui entendida como proposições que, apesar de muito menos articuladas que as proposições científicas, são divulgadas como equipolentes ou superioras a elas, ganha força diante das visões de mundo cientificista e das três críticas apresentadas a essas visões. Em especial, vamos diferenciar dois mecanismos distintos para que isso aconteça e como a Educação em Ciências tem colaborado para ambos.

\section{a) Mecanismo I: Formação de uma visão reduzida sobre a Natureza da Ciência na esfera da opinião pública.}

Um dos elos que compõem o fluxo sanguíneo da ciência é a opinião pública a visão dos membros da nossa sociedade que não participam diretamente da prática científica (Latour, 1999b), ou seja, os não-especialistas, cujo conhecimento sobre ciência é obtido, principalmente, por meio da Educação Básica. Ainda que haja outras formas de divulgação científica, é na escola que a maioria das pessoas recebe seu conhecimento sobre não somente os conteúdos da ciência, mas (ainda que implicitamente) sobre o que é a ciência.

28 Na pesquisa em Educação em Ciências, existem diversos trabalhos que se valem da TAR como fundamentação teórico-metodológica. Tal perspectiva permite a investigação de diferentes temas, como atividades didáticas (Candela, 2010; Coutinho et al., 2014; Coutinho et al., 2016), projetos científicos (Faria, \& Coutinho, 2015), texto didático (Coutinho, \& Silva, 2014), laboratório estudantil (Rezzadori, \& Oliveria, 2011) e de conteúdo (Pierce, 2015; Van Eijck, 2010). Ainda, há propostas de elaboração de unidades didáticas a partir da TAR (Coutinho, \& Silva, 2016). 
Desta forma, a educação científica não pode ser pensada como algo apartado da ciência, mas como elemento de sua própria rede (Weinstein, 2008). Não existe uma ciência "lá", dentro dos laboratórios, enquanto nós, "aqui", na escola, apenas a divulgamos ou a transmitimos. A educação científica forma a opinião pública, que, por sua vez, medeia o desenvolvimento científico.

A partir de tal compreensão, pode-se constatar que a noção de ciência herdada pela opinião pública por meio da Educação em Ciências é ainda a visão absolutista, da ciência como prática conservadora (Lemke, 2011), positivista (Kinchelo, e \& Tobin, 2009), objetiva e salvadora da humanidade (Deconto, 2014). Ao fazer isso, pode-se imaginar que se está fortalecendo as ciências. Entendemos, pelo contrário, que tal retrato termina por fragilizá-la. Isso porque, como vimos, a ciência depende da mediação humana, lida com fatiches e não fatos, envolve disputas políticas e aspectos subjetivos. Não são as supostas Objetividade e Universalidade (com O e U maiúsculos) que são os pontos fortes das ciências, mas sim o fato de ela articular redes extensas.

Assim, se a opinião pública assume como definição de ciências a Ciência com C maiúsculo, toda vez que alguém aponta o lado politizado (Sociologia dos Cientistas), as influências sociais (PFS) e as estratégias discursivas (Pós-Modernismo), gera-se descrédito sobre a validade daquele conhecimento. Assim, toda vez que a Educação em Ciências retrata a ciência como algo apenas do mundo natural, produz uma apresentação reduzida e termina por fragilizar a própria ciência, pois bastará que os grupos interessados revelem a dimensão política de determinado grupo científico para diminuir sua credibilidade perante a opinião pública. Propostas de Educação em Ciências que se alinhem às três críticas (demos alguns exemplos ao longo do texto) também fragilizam as ciências, pois não levam em conta o papel dos não-humanos na construção da nossa sociedade, apresentando, também, uma visão reducionista ${ }^{29}$. Assim, em síntese, o primeiro mecanismo de fragilização das ciências (o que por consequência fortalece outras visões) é a apresentação de uma visão reduzida sobre sua natureza, prática que vem sendo implementada pela Educação em Ciências tradicional.

\section{b) Mecanismo II: Apagamento da rede que sustenta as proposições científicas}

Como Latour e Woolgar (1986) apontam, algo se torna um "fato" autônomo quando a rede que o articulou é totalmente apagada dos textos científicos. Os "micróbios de Pasteur" só viram "micróbios da natureza" quando não precisarmos mais lembrar todos os experimentos e teorias que Pasteur precisou mobilizar. Isso é um processo natural: conforme o actante se articula com a rede ele se torna independente. Tal autonomia, entretanto, tem um efeito colateral quando chega para opinião pública, pois, embora a comunidade científica tenha acompanhado o processo de estabilização e autonomização daquele actante, a população costuma ser apresentada ao actante já estabilizado.

29 Não significa que elas estejam erradas, mas estão contando apenas "uma parte" da história. Conforme preconizado pela Cartografia das Controvérsias, devemos tentar nos aproximar de um ator pelo maior número possível de formas (Latour et al., 2012). 
Lima et al. (2018) discutem, por exemplo, como o fóton, apesar de passar por mais de 80 anos de controvérsias, articulações e desarticulações, é apresentado por livros didáticos como um actante da natureza, apagando maior parte da rede que o articulou. Nesse caso, os autores dos livros didáticos valem-se de um discurso positivista e de autoridade para sustentar sua narrativa sobre o fóton (Lima, Ostermann, \& Cavalcanti, 2017; Lima et al., 2018b) e apenas informam aos alunos sua existência sem explicitar sua articulação. Esse "apagamento" da rede pela Educação Científica é representado na Figura 5.

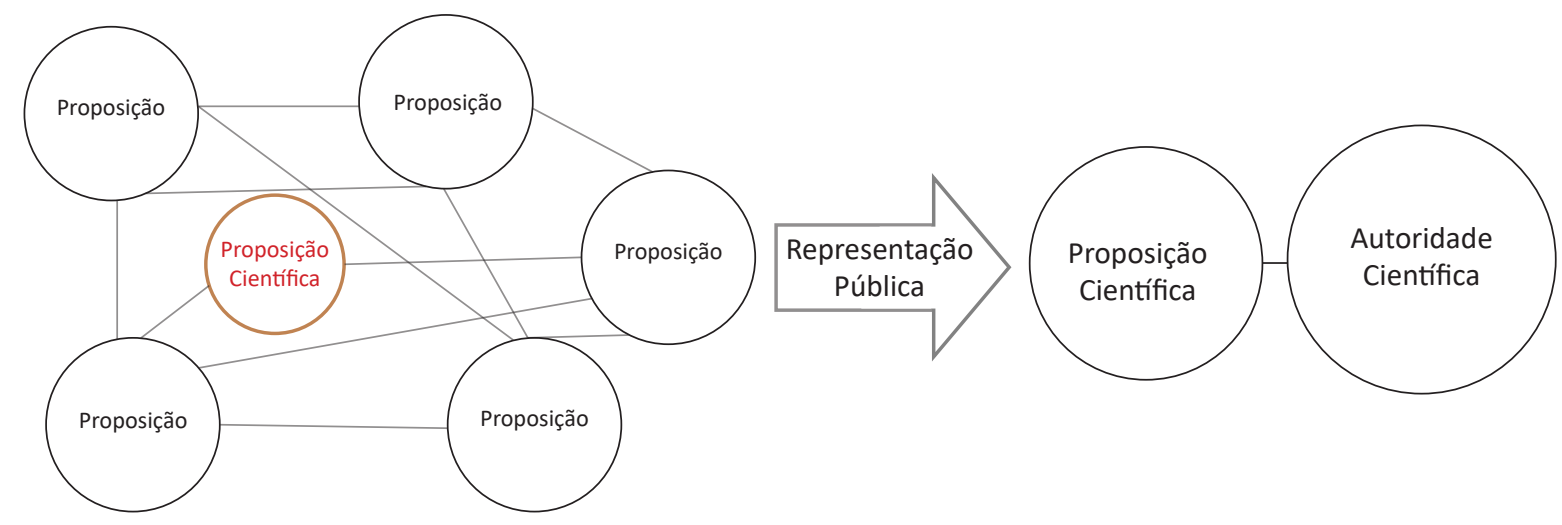

Figura 5. Apagamento da rede da ciência pela Educação Científica no processo de representação pública. A figura é meramente ilustrativa. Imagine que no lado esquerdo da flecha, existe uma rede extremamente extensa.

A partir da metafísica ecológica, percebe-se que tal apagamento tira da ciência seu "verdadeiro poder" - a rede que sustenta suas proposições. Ao enunciar as proposições científicas como autônomas, desconectamo-las das redes, retirando qualquer âncora na realidade. A escrita dos livros didáticos é inspirada numa visão de mundo moderna, que toma o polo natureza como fonte de verdade (metafísica da Ontologia); obscurecendo, portanto, que a garantia da validade de uma proposição se dá por sua rede, o que é explicado pela metafísica da ecologia.

Assim, os livros didáticos, por um lado, enfatizam a falsa neutralidade e objetividade da ciência (aquilo que não é seu ponto forte) e, por outro, não traçam as redes que sustentam os actantes (aquilo que garante a validade da ciência). O perigo de tal prática se concretiza quando grupos alternativos, que articulam proposições em redes menos extensas, seguindo o mesmo caminho, apresentam para opinião pública sua proposta sem traçar as redes que a sustentam e, assim, a colocam como equipolente à versão científica, o que representamos na Figura 6. 


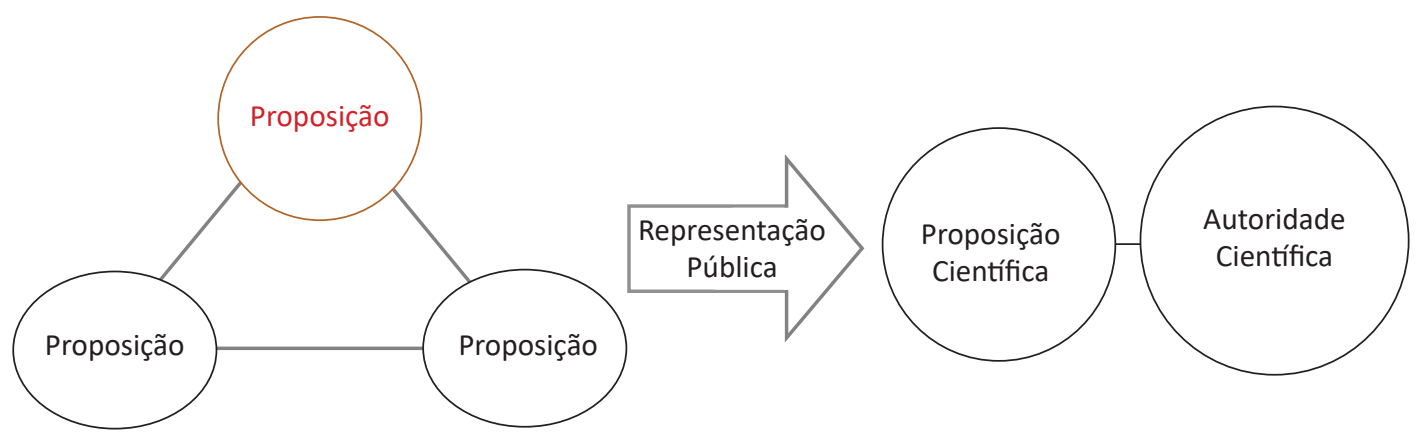

Figura 6. Proposição menos articulada, pouco aceita pela comunidade científica, sendo apresentada para opinião pública como equipolente à versão científica.

A opinião pública tem recebido da Educação em Ciências apenas o lado direito da seta da figura 5. Quando grupos alternativos apresentam sua versão, eles o fazem por meio do lado direito da seta da figura 6. Por exemplo, pode-se perceber que, nas notícias sobre cura quântica, usualmente o enunciador é apresentado como um pesquisador, doutor, membro de alguma universidade importante na Europa ou Estados Unidos. Assim, para a população leiga, a proposição representada na figura 6 é equipolente à da figura 5. Ao omitirmos a mediação de humanos e não-humanos na articulação da rede na Educação em Ciências, impedimos que a sociedade valorize o difícil trabalho das ciências, seu trabalho oficioso, a articulação das redes. Esse caminho permite que qualquer proposição seja apresentada como uma verdade científica, e a opinião pública tem, então, dificuldade de distinguir as diversas proposições.

No caso do terraplanismo, exemplo dado neste artigo, pode-se notar que alunos ou pessoas fora do meio acadêmico, quando são perguntadas sobre o formato da Terra, costumam responder "redonda". Quando perguntadas sobre como elas sabem isso, respondem "porque aprendi assim". Ou seja, de forma semelhante ao que Lima et al. (2018) apontam com relação aos fótons, as pessoas são informadas de que a Terra é redonda, mas não sabem como tal proposição é articulada.

\section{Educação em Ciências subsidiada por uma metafísica Ecológica}

Já existem diferentes e importantes contribuições para Educação em Ciências a partir do legado de Bruno Latour. A começar pela recomendação dos primeiros artigos publicados no Brasil sobre o filósofo francês (Vianna, \& Carvalho, 2001b, 2001a) de se extrapolar o ensino do conteúdo científico, aproximando o aluno da prática científica. Tal proposta também é encontrada na literatura internacional (Mody, 2015). Colocando em termos do que foi discutido, isso significa não reduzir a Natureza da Ciência ao discurso que é feito sobre ela, explicitando as práticas que são realizadas pela ciência oficiosa. Ademais, Mody (2015) recomenda a adoção de práticas científicas na Educação em Ciências como privilegiar a escrita e leitura de textos científicos, e Massoni e Moreira (2017) indicam a necessidade de trazer a ciência contemporânea para a sala de aula. Ainda, pode-se encontrar a proposta de trazer o aspecto da construção social do conhecimento para as discussões didáticas (Richard, \& Bader, 2010) e proposta de 
elaboração de sequências didáticas a partir de uma concepção ator-rede (Coutinho, \& Silva, 2016).

O que queremos propor neste trabalho, entretanto, é algo mais simples. Porém, isso não significa que seja mais fácil. A única sugestão que pretendemos fazer é que se mude a base metafísica no discurso sobre a ciência, abandonando o contrato modernista que separa natureza e sociedade. Com isso, propomos o abandono do primado da ontologia, em favor do primado da ecologia. Fazer isso significa reconhecer que aquilo que sustenta a realidade de uma proposição científica é a rede que ela articula. Assim, ao invés de informar sobre a existência de um actante e, a partir disso, instrumentalizar os alunos a resolver problemas e listas de exercícios ou fazê-los decorar informações sobre tal actante, propomos que o foco do ensino seja evidenciar a rede que sustenta tal proposição e as controvérsias sociocientíficas que conduziram ou conduzem à sua articulação. Isto é, tentar mostrar como que foi possível para aquela proposição vir à existência.

Não existe caminho óbvio ou trivial para se fazer isso, e propostas didáticas que adotem tal visão podem variar desde uma estratégia mais "tímida" até a adoção da Cartografia das Controvérsias e da Teoria Ator-Rede como já vem sendo feito na literatura (Coutinho, \& Silva, 2016; Faria, \& Coutinho, 2015).

Portanto, nosso objetivo não é fazer recomendações; mas levantar possíveis olhares sobre como se engajar em uma Educação em Ciências em tempos de pósverdade. Assim, por exemplo, ao invés de se adotar uma abordagem instrumentalista ou informativa, como a dos livros didáticos, podemos procurar uma estratégia didática articuladora. Isto é, ao invés de ensinar simplesmente que a Terra é redonda ou que vacinas funcionam, pode-se discutir quais são as evidências que sustentam tais ideias (desnaturalizando a noção de que se está diante de um fato autônomo e óbvio, mas de uma proposição que é articulada com uma rede de dados, experimentos, teorias, equipamentos e cientistas) e como essa rede tenta ser desarticulada por programas concorrentes e vice-versa. Nesse contexto, pode-se discutir, também, as questões de poder e de disputa que envolvem a prática científica. Usando os termos latourianos, isso é equivalente a abrir a caixa preta da ciência (Latour, 1988a).

Ao adotar tais medidas, estamos contribuindo para dirimir os dois mecanismos de criação de pós-verdade explicados anteriormente. Ao atar os atores em suas redes, mostramos, gradualmente, que aquilo que fortalece uma proposição científica é a rede que ela articula e não uma suposta objetividade. Assim, quando propostas alternativas se apresentarem para a opinião pública elas terão que mobilizar uma rede satisfatória para fazer frente ao que já foi autonomizado pela ciência. Ao explicitar as disputas políticas e sociais existentes dentro da ciência como algo normal à prática científica e que não fere sua "qualidade" - mudamos, paulatinamente, o conceito sobre ciência que a opinião pública pode ter; diminuindo a chance de que pesquisas sejam diminuídas por atributos que são indispensáveis para sua sustentação. Isso não garante, obviamente, que as pósverdades serão abandonadas; mas, simplesmente, contribui para formação de cidadãos 
com maior possibilidade de desenvolver um olhar reflexivo sobre o conhecimento que lhe é apresentado. Ademais, quão longe o professor quer e pode ir dentro da caixa de Pandora depende de seu contexto de trabalho e deve ser ponderado por ele mesmo. $\mathrm{O}$ objetivo básico, entretanto, é simplesmente reatar os atores em suas redes, garantindo a materialidade de sua existência.

\section{Considerações Finais}

Neste trabalho, propusemos uma reflexão sobre a formação de pós-verdades e o papel da Educação em Ciências em tal cenário. Partindo da definição dada pelo dicionário Oxford em 2016, quando pós-verdade foi escolhida palavra do ano, trouxemos reflexões metafísicas sobre o a ciência moderna e suas principais críticas (a Sociologia dos Cientistas, o Programa Forte da Sociologia e o Pós-Modernismo) a partir dos Estudos da Ciência de Bruno Latour (1983, 1988a, 1993, 2001, 2004b, 2005, 2016, 2017; Latour et al., 2012). Apresentamos, também, uma visão metafísica alternativa desenvolvida por Latour e colaboradores a partir de seus estudos etnográficos e historiográficos em dialogia com a Sociologia Monadal de Gabriel Tarde (Tarde, 2007), a Sociologia Simétrica de Michel Callon (1984) e a Filosofia das Proposições de Alfred Whitehead (1978).

A partir dessa outra metafísica, a qual Latour (2001) denomina de Ecologia, pode-se redefinir o conceito de pós-verdade; não sendo mais o confronto de um conhecimento com uma crença (ou fato versus fetiche); mas o enfretamento de duas proposições que, apesar de articularem redes de diferentes extensões, são apresentadas à opinião pública como equipolentes. Propusemos dois mecanismos que são usados para enfraquecer as proposições científicas, levando à conclusão de que um ensino científico com viés epistemológico absolutista acaba por enfraquecer a própria ciência ao invés de fortalecê-la, como se poderia pensar em princípio. Desta forma, argumentamos que tanto as visões absolutistas quanto as visões relativistas contribuíram para o cenário de formação de pós-verdades.

A proposta que fazemos, em dialogia com a pesquisas em Educação em Ciências que já trazem uma vasta reflexão sobre a obra de Latour (Candela, 2010; Coutinho et al., 2014; Coutinho et al., 2016; Coutinho, \& Silva, 2014, 2016; Massoni, \& Moreira, 2017; Mody, 2015; M. A. Oliveira, 2010; Queiroz, \& Almeida, 2004; Rezzadori, \& Oliveria, 2011; Richard \& Bader, 2010; Roth \& Tobin, 1997; Roxael et al., 2015; Vianna, \& Carvalho, 2001a, 2001b; Weinstein, 2008), passa por realizar um investimento em uma virada metafísica. Não queremos com isso fazer uma "proposta latouriana" de ensino. Sugerimos tão somente que, reconhecendo que a existência de uma proposição é garantida pela rede que a articula, a educação passe a explicitar tais redes, conectando as proposições com a materialidade sociotécnica que a sustenta. Ao fazer isso, estaremos contribuindo para a formação de uma concepção de ciências mais próxima de seu exercício oficioso, enfraquecendo os dois mecanismos de formação de pós-verdade. 
Neste período em que, cada vez mais, a ação humana se emaranha com a dos nãohumanos, o que alguns têm chamado de Antropoceno (Arènes et al., 2018; Latour, 2014; Latour, \& Lenton, 2018), pensar sobre as relações entre ciência, sociedade e tecnologia não é uma questão de interesse puramente intelectual, algo para ser feito nos recantos das faculdades de Humanidades. A "natureza" é um ator sobre o qual se toma decisões na esfera política e pública e, nesse cenário, os especialistas passam a desempenhar um papel relevante. $\mathrm{O}$ equilíbrio justo a ser buscado é a possibilidade de dialogar com tais cientistas sem ter que ser subserviente a um discurso absolutista, nem recair numa visão relativista. $\mathrm{O}$ equilíbrio justo é trazer a ciência para a democracia (Latour, 2004a). Para que isso seja feito de forma proveitosa e segura, é necessário que haja um amadurecimento por parte da opinião pública não somente sobre o conhecimento científico, mas sobre a própria Natureza da Ciência, e a Educação em Ciências tem um papel crucial nesse processo. Como fazer isso? Deixamos uma indicação do próprio Latour: "Agora, cientistas têm que ganhar respeito de volta. Mas a solução é a mesma: você precisa mostrar a ciência como ciência em ação. Eu concordo que é arriscado, porque nós tornamos as incertezas e controvérsias explícitas." (Vrieze, 2017, tradução nossa). Longe de querer encerrar a questão, esperamos que o presente trabalho contribua para o debate sobre o tema e para o amadurecimento de nossa responsabilidade política enquanto educadores e pesquisadores em Educação em Ciências.

\section{Agradecimentos}

A terceira e a quinta autora agradecem ao Conselho Nacional de Pesquisa (CNPq) pelo apoio oferecido.

\section{Referências}

Alvim, M. (2017). Quem são e o que pensam os brasileiros que acreditam que a Terra é plana. Recuperado em, 25 de agosto, 2018, de https://www.bbc.com/portuguese/ brasil-41261724

Arènes, A., Latour, B., \& Gaillardet, J. (2018). Giving depth to the surface: An exercise in the Gaia-graphy of critical zones. The Anthropocene Review, 5(2),120-135

Auler, D., \& Delizoicov, D. (2001). Alfabetização científico-tecnológica pra quê? Ensaio - Pesquisa Em Educação Em Ciências, 3(1), 122-134.

Bachelard, G. (1996). A Formação do Espírito Científico. Rio de Janeiro: Contraponto.

Bagdonas, A., Zanetic, J., \& Gurgel, I. (2014). Controvérsias sobre a natureza da ciência como enfoque curricular para o ensino da física: o ensino de história da cosmologia por meio de um jogo didático. Revista Brasileira de História Da Ciência, 7(2), 242-260.

Barthes, R. (1982). Empire of Signs. New York: The Noonday Press. 
Bloor, D. (1991). Knowledge and Social Imagery. Chicago: The University of Chicago Press.

Bloor, D. (1999). Anti-Latour. Studies History and Philosophy of Science, 30(1), 81-112.

Bourdieu, P. (1976). Le Champ Scientifique. Actes de La Recherche En Sciences Sociales, 2(2-3), 88-104.

Bourdieu, P. (1997). Os usos sociais da ciência. São Paulo: Editora UNESP.

Callon, M. (1984). Some elements of a sociology of translation: domestication of the scallops and the fishermen of St Brieuc Bay. The Sociological Review, 32, 196-233.

Candela, A. (2010). Time and Space: undergraduate Mexican physics in motion. Cultural Studies of Science Education, 5(3), 701-727.

Carson, R. (1994). Silent Spring. Robbisdale: Fawcett Publications.

Corrêa, A. (2014). Movimento antivacina gera surto de doenças nos EUA. Recuperado em 22 de setembro, 2018, de https://www.bbc.com/portuguese/noticias/2014/02/140221_ vacinas_doencas_dg

Coutinho, F. A., Goulart, M. I. M., Munford, D., \& Ribeiro, N. A. (2014). Seguindo uma lupa em uma aula de ciências para a educação infantil. Investigações Em Ensino de Ciências, 19(2), 381-402.

Coutinho, F. A., Santos, V. M. D. F., Amaral, A. C. R., Santos, M. I., Silva, F. A. R., \& Silva, A. D. J. (2016). Quando os educandos transformam uma sequência didática em um ator-rede: movimentos de translação entre ciência, tecnologia, sociedade e ambiente na educação de jovens e adultos. Experiências Em Ensino de Ciências, 11(3), 178-193.

Coutinho, F. A., \& Silva, F. A. R. (2014). Análise de texto de um livro diático de biologia orientada pela teoria ator-rede: um estudo sobre o tema evolução biológica. Investigações Em Ensino de Ciências, 19(3), 531-539.

Coutinho, F. A., \& Silva, F. A. R. (2016). Sequências didáticas: propostas, discussões e reflexões teórico-metodológicas. Belo Horizonte: FAE/UFMG.

Dahmen, S. (2006). Einstein e a Filosofia. Revista Brasileira de Ensino de Física, 28(1), 3-7.

Deconto, D. C. S. (2014). A perspectiva ciência, tecnologia e sociedade na disciplina de metodologia do ensino de física: um estudo na formação de professores à luz do referencial sociocultural. Universidade Federal do Rio Grande do Sul.

Derrida, J. (1997). Of Grammatology (Vol. 87). Baltimore: The John Hopkins University Press.

Eco, U. (1981). Lector in fabula. La cooperación interpretativa en el texto narrativo. Barcelona: Editorial Lumen. 
Einstein, A. (2006). Física e Realidade. Revista Brasileira de Ensino de Física, 28(1), 9-22. Fabricius, W. V. (1983). Piaget's theory of knowledge: Its philosophical context. Human Development, 26(6), 325-334. https://doi.org/10.1159/000272894

Faria, S. E., \& Coutinho, A. F. (2015). Educação Científica em ação: a cartografia das controvérsias como prática de cidadania técnico-científica. Caderno de Pesquisa, 22(3), 133-147.

Feyerabend, P. (2010). Adeus à Razão. São Paulo: Editora UNESP.

Goldstein, R. (2008). Incompletude: A prova e o paradoxo de Kurt Gödel. São Paulo: Companhia das Letras.

Greimas, A. J., \& Courtés, J. (1982). Semiotics and Language. Bloomington: Indiana University Press.

Harman, G. (2009). Prince of Networks: Bruno Latour and Metaphysics. Melbourne: re.press.

Idoeta, P. A. (2018). Por que nem sempre adianta apresentar fatos contra notícias falsas. Recuperado em 22 de setembro, 2018, de https://www.bbc.com/portuguese/ brasil-44686833

Junges, A., \& Massoni, N. T. (2018). O Consenso Científico sobre Aquecimento Global Antropogênico: Considerações Históricas e Epistemológicas e Reflexões para o Ensino dessa Temática. Revista Brasileira de Pesquisa Em Educação Em Ciências, 18(2),455-491.

Kant, I. (2005). Crítica da Razão Pura. São Paulo: Martin Claret.

Kant, I. (2009). An Answer to the question: 'what is enlightment?". London: Penguin.

Kincheloe, J. L., \& Tobin, K. (2009). The much exaggerated death of positivism. Cultural Studies of Science Education, 4(3), 513-528.

Knor-Cetina, K. (1981). The manufacture of knowledge: an essay on the constructivist and contextual nature of science. In Science Observed:perspectives on the study of science. London: Sage.

Kuhn, T. (1963). The function of dogma in Scientific Research. In A. C. Crombie (Ed.), Scientific Change (pp. 347-369). London: Heinemann.

Kuhn, T. (1977). The Essential Tension: Selected Studies in Scientific Tradition and Change. Chicago: Chicago University Press.

Kuhn, T. (1996). The structure of Scientific Revolutions (Terceira). Chicago: The University of Chicago Press.

Laclau, E. (2014). The Rhetorical Foundations of Society. New York: Verso.

Lakatos, I. (1978). The Methodology of Scientific Research programmes(Vol. 1). Cambridge: Cambridge University Press. 
Lang, F. (1989). A Filosofia de Karl Popper e suas Implicações no Ensino de Ciência. Caderno Catarinense de Ensino de Física, 6(2), 148-162.

Lang, F. (1996). A Filosofia da Ciência de Karl Popper: o Racionalismo Crítico. Caderno Catarinense de Ensino de Física, 5(2), 9-28.

Lang, F. (2002). A Teoria Do Conhecimento De Kant: O Idealismo Transcendental. Caderno Brasileiro de Ensino de Física, 28-51.

Lang, F., \& Ostermann, F. (2002). A Insustentabilidade da Proposta Indutivista de "Descobrir a Lei a partir de Resultados Experimentais." Caderno Catarinense de Ensino de Física, 19(número especial), 7-27.

Latour, B. (1983). Give me a laboratory and I will raise the world. In K. Knorr-Cetin \& M. Mulkay (Eds.), Science Observed: perspectives on the study of science (pp. 141-169). Bervely Hills: Sage.

Latour, B. (1988a). Science in Action: How to follow scientists and engineers through society. Cambridge: Harvard University Press.

Latour, B. (1988b). The Pasteurization of France. Massachussets: Harvard University Press.

Latour, B. (1992). One more turn after the social turn. In E. McMullin (Ed.), The Social Dimensions of Science (pp. 272-292). Notre Dame: Notre Dame University Press.

Latour, B. (1993). We have never been modern. Cambridge: Harvard University Press.

Latour, B. (1996). On Interobjectivity. Mind, Culture, and Activity, 3(4), 228-245.

Latour, B. (1999a). For David Bloor... and Beyond: A Reply to David Bloor's "Anti-Latour." Studies History and Philosophy of Science, 30(1), 113-129.

Latour, B. (1999b). Pandora's Hope: Essays on the reality of Science Studies. Cambridge: Harvard University Press.

Latour, B. (1999c). Pasteur on lactic acid yeast: a partial semiotic analysis. Configurations, $1(1), 129-146$.

Latour, B. (2000). Berlin key or how to do words with things. In P. M. Graves-Brown (Ed.), Matter, Materiality and culture (pp. 10-21). London: Routledge.

Latour, B. (2001). Gabriel Tarde and the End of Sociocultural. In P. Joyce (Ed.), The Social in Question. New Bearings in History and the Social Sciences (pp. 117-132). London: Routledge.

Latour, B. (2004a). Politics of Nature: How to bring Science into Democracy. Cambridge: Harvard University Press.

Latour, B. (2004b). Why Has Critique Run out of Steam? From Matters of Fact to Matters of Concern. Critical Inquiry, 30(2), 225-248. 
Latour, B. (2005). Reassembling the Social: An Introduction to Actor Network Theory. Oxford: Oxford University Press.

Latour, B. (2013). Jamais Fomos Modernos. São Paulo: Editora 34.

Latour, B. (2014). Para distinguir amigos e inimigos no tempo do Antropoceno. Revista de Antropologia, 57(1), 11-31.

Latour, B. (2016). Cogitamus: Seis Cartas sobre as Humanidades Científicas. São Paulo: Editora 34.

Latour, B. (2017). A Esperança de Pandora. São Paulo: Editora da UNESP.

Latour, B., Jensen, P., Venturini, T., Grauwin, S., \& Boullier, D. (2012). "The whole is always smaller than its parts" - a digital test of Gabriel Tardes' monads. British Journal of Sociology, 63(4), 590-615.

Latour, B., \& Lenton, T. M. (2018). Extending the domain of freedom, or why Gaia is so hard to understand. Critical Inquiry, no prelo.

Latour, B., \& Woolgar, S. (1986). Laboratory Life: The construction of scientific facts. Princeton: Princeton University Press.

Latour, B., \& Woolgar, S. (1997). A vida de laboratório: a produção dos fatos científicos. Rio de Janeiro: Relume Dumará.

Law, J. (1984). On the methods of long-distance control: Vessels, navigation and the Portuguese route to India. Sociological Review, 32(S1), 234-263.

Lemaine, G., Macleod, R., Mulkay, M., \& Weingart, P. (1976). Perspectives on the emergence ofscientific disciplines. La Haye: Mouton/Aldine.

Lemaine, G., \& Matalon, B. (1969). La lutte pour da vie dans la cite scientifique. Revue Française de Sociologie, (10), 139-165.

Lemke, J. (2011). The secret identity of science education: masculine and politically conservative?, 287-292.

Lightman, B. (2016). A Companion to the History of Science. Oxford: John Willey and Sons.

Lima Junior, P., Pinheiro, N., \& Ostermann, F. (2012). Bourdieu en la educación científica: consecuencias para la enseñanza y la investigación. Didáctica de Las Ciencias Experimentales y Sociales, (26), 145-160.

Lima, N. W., \& Nascimento, M. M. (2018). Terapias integrativas: uma disputa epistemológica e política. In XVII Encontro de Pesquisa em Ensino de Física (pp. 1-8). Campos do Jordão.

Lima, N. W., Ostermann, F., \& Cavalcanti, C. J. de H. (2017). Física Quântica no ensino médio: uma análise bakhtiniana de enunciados em livros didáticos de Física aprovados no PNLDEM 2015. Caderno Brasileiro de Ensino de Física, 435-459. 
Lima, N. W., Ostermann, F., \& Cavalcanti, C. J. de H. (2018a). A não-modernidade de Bruno Latour e suas implicações para a Educação em Ciências. Caderno Brasileiro de Ensino de Física, 35(2), 367-388.

Lima, N. W., Souza, B. B. De, Cavalcanti, C. J. de H., \& Ostermann, F. (2018b). Um Estudo Metalinguístico sobre as Interpretações do Fóton nos Livros Didáticos de Física Aprovados no PNLDEM 2015: Elementos para uma Sociologia Simétrica da Educação em Ciências. Revista Brasileira de Pesquisa Em Educação Em Ciências, 18(1), 331-364.

Lopes, A. C. (2013). Teorias Pós-Críticas, política e currículo. Educação, Sociedade e Culturas, 39, 7-23.

Lopes, A. C., \& Macedo, E. (2011). Teorias de Currículo. São Paulo: Cortez.

Lopes, A. R. C. (1996). Bacehlard: O Filósofo da Desilusão. Cader, 13(3), 248-273.

Lorenzi, B. R., \& Andrade, T. N. de. (2011). Latour e Bourdieu: rediscutindo as controvérsias. Teoria \& Pesquisa: Revista de Ciência Política, 20(2), 107-121.

Lynch, M. (1985). Art and Artifact in the laboratory science: a study of shopwork and shoptalk in a research laboratory. London: Routledge.

Martins, R. de A., Silva, C. C., Martins, R. de A., \& Silva, C. C. (2015). As pesquisas de Newton sobre a luz: Uma visão histórica. Revista Brasileira de Ensino de Física, 37(4), 4202-1-4202-4232.

Massoni, N. T., \& Moreira, M. A. (2017). A Visão Etnográfica De Bruno Latour Da Ciência Moderna E a Antropologia. Revista Brasileira de Ensino Ciência e Tecnologia, 10(3), 61-80.

Mcintyre, L. (2018). Post-Truth. Cambridge: MIT Press.

Mitroff. (1974). The subjective side of Science. New York: Elsevier.

Mody, C. C. M. (2015). Scientific Practice and Science Education. Science Education, 99(6), 1026-1032.

Moura, C. B. de, \& Guerra, A. (2016). Cultural History of Science: A Possible Path for Discussing Scientific Practices in Science Teaching? Revista Brasileira de Pesquisa Em Educação Em Ciências, 16(3), 749-771.

Oliveira, M. A. (2010). Alfabetização Científica no Clube de Ciências do Ensino Fundamental: Uma Questão de Inscrição. Revista Ensaio, 12(02), 11-26.

Oliveira, R. A., \& Silva, A. P. B. (2012). História da Ciência e Ensino de Física. In História da Ciência e Ensino de Física (pp. 41-64). Natal: Editora da UFRN.

Otte, M. (1998). Limits of constructivism: Kant, Piaget and Peirce. Science and Education. 7(5), 425-50. 
Oxford Dictionary. (2016). Oxford Dictionary 2016 word of the year. Recuperado em 22 de setembro, 2018, de https://en.oxforddictionaries.com/word-of-the-year/word-ofthe-year-2016

Pêcheux, M. (1997). Semântica e discurso: uma crítica à afirmacao do óbvio. Campinas: Editora da UNICAMP.

Peduzzi, L. O. Q., Martins, A. F. P., \& Ferreira, J. M. H. (2012). Temas de História e Filosofia da Ciência no Ensino. Natal: Editora da UFRN.

Pessoa Jr., O. (2009). A Classificação das Diferentes Posições em Filosofia da Ciência. Cognitio-Estudos: Revista Eletrônica de Filosofia. 6(1), 54-60.

Pierce, C. (2015). Learning about a fish from ANT: acotr network theory and science education in the postgenomic era. Cultural Studies of Science Education, 10, 83-107.

Polanyi, M. (1946). Science, faith and society. London: Oxford University Press.

Ponczek, R. L. (2000). A polêmica entre Leibniz e os cartesianos: MV ou MV2? Cad. Cat. Ens. Fis., 17(3), 336-347.

Popper, K. (2008). Conjecturas e Refutações. Brasilia: Editora Universidade de Brasília.

Porto, C. M., \& Porto, M. B. D. S. M. (2009). Galileu, Descartes e a elaboração do princípio da inércia. Revista Brasileira de Ensino de Física, 31(4), 46011-460110.

Queiroz, S. L., \& Almeida, M. J. P. M. (2004). Do fazer ao compreender ciências: reflexões sobre o aprendizado de alunos de iniciação científica em química. Ciência \& Educação, $10,41-53$.

Rezzadori, C. B. D. B., \& Oliveria, M. A. (2011). A Rede Sociotécnica de um Laboratório de Química do Ensino Médio. Experiências Em Ensino de Ciências, 6(3), 16-37.

Richard, V., \& Bader, B. (2010). Re-presenting the social construction of science in light of the propositions of Bruno Latour: For a renewal of the school conception of science in secondary schools. Science Education, 94(4), 743-759.

Roth, W. M., \& Tobin, K. (1997). Cascades of inscriptions and the representation of nature: how numbers, tables, graphs and money come to re-present a rolling ball. International Journal of Science Education, 19(9), 1075-1091.

Roxael, F. R., Diniz, N. D. P., \& Oliveira, J. R. S. D. (2015). O Trabalho do Cientista nos Cartuns de Sidney Harris: Um Estudo sob a Perspectiva da Sociologia da Ciência. Química Nova Na Escola, 37(número especial), 68-81.

Santos, B. de S., \& Meneses, M. P. (2009). Epistemologias do Sul. Coimbra: Edições Almedina SA.

Schinkel, W. (2007). Sociological discourse of the relational: The cases of Bourdieu \& Latour. Sociological Review, 55(4), 707-729. 
Searle, J. R. (2004). Mind: A Brief Introduction. Oxford: Oxford University Press.

Slezak, P. (1994). Sociology of Scientific Knowledge and Science Education part 2: Laboratory Life Under Microscope. Science \& Education, 3, 329-355.

Strum, S., \& Latour, B. (1987). The meaning of social: From Baboons to Humans. Social Science Information, 26(4), 783-802.

Tarde, G. (2007). Monadologia e Sociologia - e outros ensaios. São Paulo: Cosac Naify.

Valadares, J. (2011). A teoria da aprendizagem significativa como teoria construtivista. Aprendizagem Significativa Em Revista, 1(1), 36-57.

Van Eijck, M. (2010). Addressing the Dynamics of Science in Curricular Refeorm for Scientific Literacy: The Case of Genomics. International Journal of Science Education, 32(18), 2429-2449.

Venturini, T. (2010). Diving in magma: how to explore controversies with actor-network theory. Public Understanding of Science, 19(3), 258-273.

Venturini, T. (2012). Building on faults: How to represent controversies with digital methods. Public Understanding of Science, 21(7), 796-812.

Vianna, D. M., \& Carvalho, A. M. P. (2001a). Bruno Latour e contribuições da antropologia da Ciência: Aspectos para o Ensino de Ciências. Ciência e Ensino, 10, 14-19.

Vianna, D. M., \& Carvalho, A. M. P. (2001b). Do fazer ao ensinar ciências: a importÂncia dos episódios de pesquisa na formação de professores. Investigações Em Ensino de Ciências, 6(1), 111-132.

Videira, A. A. P. (2007). Historiografia e história da ciência. Escritos, 1(1), 111-158.

Vrieze, J. (2017). Bruno Latour, a veteran of the 'science wars', has a new mission. Science. Recuperado, em 22 de setembro, 2018, de http://www.sciencemag.org/news/2017/10/ latour-qa

Weinstein, M. (2008). Finding Science in the school body: Reflections on transgressing the boundaries of science education and the social studies of science. Science Education, 92(3), 389-403.

Whitehead, A. N. (1978). Process and Reality: An Essay in Cosmology. New York: The Free Press.

Wittgenstein, L. (1968). Tratactus Logico-Philosophicus. São Paulo: Companhia Editora Nacional.

Woolgar, S. (1982). Laboratory Studies: a comment on the state of the art. Social Studies of Science, 12, 481-498. 
Nathan Willig Lima

${ }^{(0)}$ https://orcid.org/0000-0002-0566-3968 Universidade Federal do Rio Grande do Sul (UFRGS) Porto Alegre, RS, Brasil Centro Federal de Educação Tecnológica Celso Suckow da Fonseca (CEFET/RJ) Rio de Janeiro, RJ, Brasil lima.nathan@gmail.com

\section{Pedro Antônio Viana Vazata}

https://orcid.org/0000-0001-8780-5343 Universidade Federal do Rio Grande do Sul (UFRGS) Porto Alegre, RS, Brasil pedrospring@hotmail.com

Fernanda Ostermann

${ }^{-}$https://orcid.org/0000-0002-0594-2174 Universidade Federal do Rio Grande do Sul (UFRGS) Porto Alegre, Rio Grande do Sul, Brasil fernanda.ostermann@ufrgs.br

\section{Claudio José de Holanda Cavalcanti}

${ }^{0}$ https://orcid.org/0000-0002-2477-3150 Universidade Federal do Rio Grande do Sul (UFRGS) Porto Alegre, Rio Grande do Sul, Brasil claudio.cavalcanti@ufrgs.br

\section{Andreia Guerra}

${ }^{\oplus}$ https://orcid.org/0000-0002-6397-3817 Centro Federal de Educação Tecnológica Celso Suckow da Fonseca (CEFET/RJ) Rio de Janeiro, Rio de Janeiro, Brasil andreia.guerra96@gmail.com

Submetido em 22 de Setembro de 2018 Aceito em 23 de Janeiro de 2019 Publicado em 05 de Maio de 2019 